\title{
RODRIGO AMADOR DE LOS RÍOS, TRAYECTORIA PROFESIONAL Y DIRECCIÓN DEL MUSEO ARQUEOLÓGICO NACIONAL (1911-16)
}

\author{
RODRIGO AMADOR DE LOS RÍOS, PROFESSIONAL CAREER AND DIRECTION \\ OF THE NATIONAL ARCHAEOLOGICAL MUSEUM (1911-16)
}

\author{
ALFREDO MEDEROS MARTÍN*
}

Resumen: Rodrigo Amador de los Ríos, hijo del académico José Amador de los Ríos, ingresó en el Museo Arqueológico Nacional en 1868, pero fue cesado y reingresó en 1875 . Alumno del catedrático de árabe de la Universidad de Granada, Francisco Javier Simonet, fue el principal especialista en arqueología islámica en España durante el último cuarto del siglo XIX, realizó el estudio de las inscripciones árabes de España y Portugal (1883) e ingresó en la Real Academia de Bellas Artes en 1890. En la última década del siglo XIX se encontró en su trayectoria con el ascenso de Catalina García y López, quien contaba con el apoyo del ala derecha del Partido Liberal-Conservador. Después de su muerte fue nombrado director del Museo Arqueológico Nacional entre 1911-16 y asumió la dirección de las excavaciones en Itálica (Sevilla), hasta que se jubiló.

Palabras clave: Rodrigo Amador de los Ríos, Museo Arqueológico Nacional, arqueología islámica, Itálica.

\section{LA FAMILIA DE LOS AMADOR DE LOS RÍOS}

Rodrigo Fernando Celedonio Amador de los Ríos y Fernández de Villalta nació en Madrid el 3 de marzo de 1849 en la calle de Silva 38, hijo del académico y

* Departamento de Prehistoria y Arqueología de la Universidad Autónoma de Madrid. Facultad de Filosofía y Letras. Campus de Cantoblanco. 28.049 Madrid. Correo-e: alfredo.mederos@uam.es

\begin{abstract}
Rodrigo Amador de los Rios, son of the academician José Amador de los Rios, joined the National Archaeological Museum in 1868, but he was dismissed and rejoined in 1875. Student of the Professor of Arabic at the University of Granada, Francisco Javier Simonet, he was the main specialist in Islamic archaeology in Spain during the last quarter of the nineteenth century, publishing the study of Arabic inscriptions of Spain and Portugal (1883) and joined the Royal Academy of Fine Arts in 1890. During the last decade of the nineteenth century he met on his trajectory with the rise of Catalina García Lopez, who had the support of the right wing of the Liberal-Conservative Party. After his death he was appointed as director of the National Archaeological Museum from 1911 to 1916 and assumed the direction of excavations at Italica (Seville), when he retired.
\end{abstract}

Key words: Rodrigo Amador de los Ríos, National Archaeological Museum, Islamic archaeology, Italica.

catedrático José Amador de los Ríos y Serrano (181878), natural de Baena (Córdoba) y de María Juana Fernández de Villalta, nacida en Sevilla, que se habían casado en marzo de 1840. Fue bautizado el 7 de marzo en la iglesia parroquial de San Martín. Sus tíos fueron el hermano mayor de José, Diego Manuel de los Ríos (1816-71), catedrático de Retórica y Poética en el Instituto de Segunda Enseñanza de Granada, y el hermano menor, el arquitecto Demetrio de los Ríos (1827-92). Era nieto por parte paterna de José María de los Ríos Serrano 
y Padilla (1790) y de María del Carmen Serrano, ambos de Baena. Sus abuelos maternos fueron Joaquín Fernández de Villalta, nacido en Alcolea (Sevilla) y María Josefa Gómez de Sevilla (AGA 31/06499; AHN 3579/12). Como el propio Rodrigo Amador de los Ríos (1906: 21) indica, "aún con haber nacido en Madrid, me juzgo hijo de la provincia [de Córdoba] por mi Padre" (fig. 1).

Perdió a dos hermanos en la guerra. Su hermano mayor, el médico Gonzalo Amador de los Ríos murió el 31 de junio de 1876 en La Habana, durante la guerra de Cuba, atendiendo a los enfermos de "vómito" en el hospital militar. Alfonso Amador de los Ríos, teniente de Infantería, murió por una granada en Santa Bárbara de Oteiza (Navarra) frente a los carlistas el 30 de enero de 1876 (Pavón 1978: 156; Amador de los Ríos 1879: dedicatoria; Valverde 1903/1982: 431). Su hermana mayor, Isabel Matilde Amador de los Ríos (1844), casó con el catedrático Francisco Fernández y González, al que denomina "mi hermano político" (Amador de los Ríos 1911b: 16 n. 3), aunque a veces su hermana es considerada su prima (Pasamar y Peiró 2002: 243 y 526). El último hermano, Ramiro Amador de los Ríos (1845-1900), fue arquitecto, casó con Elvira Palomino y Toledo, y fue profesor de la Escuela de Bellas Artes de Málaga.

En 1869 residía en la calle de Góngora 2, 2 derecha, con sus padres (AHN 3579/12). Rodrigo casó con Petra Cabezón Miranda, con la que tuvo 5 hijos, 2 niños y 3 niñas. La familia residía en la calle Fuencarral 109, $2^{\circ}$ izquierda en 1899 (AHN 6335/4).

El hijo mayor, Rodrigo Amador de los Ríos Cabezón, continuó la tradición de su padre (vide infra) y fue oficial de la Academia de Toledo de la promoción de 1914'. La primera hija fue María Juana Amador de los Ríos y Serrano (1881), que tenía el nombre de la abuela, seguida por otra niña, Elisa Amador de los Ríos y Cabezón (1887). Después fue Alfonso Amador de los Ríos y Cabezón (1894-1976), el único hijo que realizó estudios superiores, que también trabajó en el Museo Arqueológico Nacional, "su hijo, nuestro compañero D. Alfonso" (Anónimo 1916: 347), el cual estudió

1. Durante la Guerra Civil fue comandante de las fuerzas regulares indígenas $\mathrm{n}^{\mathrm{o}} 3$ de Ceuta, con las cuales se sublevó el 18 de julio de 1936, tomó la ciudad de Tarifa el 24 de julio, dirigió en II Tabor de Regulares de Ceuta dentro de la II columna del Comandante Castejón, acompañando a la V bandera del Tercio de la Legión, que inició el avance hacia Badajoz, la cual tomó Llerena el 5 de agosto, capturó Talavera la Real el 13 de agosto, quedó herido el 3 de septiembre y fue muerto de 24 de diciembre de 1936 en el Cerro de Garabitas (Casa de Campo, Madrid) ( $A B C$ 24-12-1939: 19) con el grado de teniente coronel de Regulares.
Bachillerato de Artes en el Instituto Cardenal Cisneros de Madrid (1896), la Licenciatura de Filosofía y Letras en la Universidad de Madrid (1899-1902) y un año más de especialización para el Cuerpo de Archivos, Bibliotecas y Museos (1902-03) en la Universidad Central (AHN 6335/4). Finalmente, la hija más pequeña, Elvira Amador de los Ríos y Cabezón (1900-98).

\section{FORMACIÓN}

Realizó los estudios primarios en el Colegio de los Jesuitas de San Isidro de Madrid y después continuó el bachillerato en Granada según Zapata (2006: 914), aunque no hay pruebas documentales. Sí conocemos que en el Instituto de Sevilla finalizó el Bachillerato en Artes con la calificación de aprobado el 23 de junio de 1864 (AHN 3579/12).

Los dos primeros años de la carrera de Filosofía y Letras los inició en la Universidad de Sevilla, primero en 1863-64 cuando cursó Historia universal, Geografía y Literatura clásica latina, las tres con calificación de mediano, el antiguo aprobado. Las dos últimas asignaturas eran comunes con el primer año de Derecho. En 1864-65 se matriculó en Estudios críticos sobre los prosistas griegos donde obtuvo un sobresaliente y $\mathrm{Me}$ tafísica, cuyo examen ya realizó en la Universidad Literaria de Granada, con la calificación de notable (AHN 6335/5), abreviación de "notablemente aprovechado". En el año académico de 1864-65 comenzó simultáneamente los estudios de Derecho en la Universidad de Sevilla, siendo común con Filosofía y Letras la de Metafísica, y matriculándose también en Derecho Romano, $1^{\circ}$ curso y en Economía Política y Estadística, dos asignaturas de las que ya se examinó en la Universidad de Granada, obteniendo en ambas un mediano o aprobado (AHN 3579/12). En Sevilla fue alumno de su Rector, Federico de Castro y Fernández, "docto maestro mío en aquella Universidad Literaria" (Amador de los Ríos 1912: 270-271), seguramente en Metafisica, materia de la que era catedrático desde 1861.

En Granada completó los estudios para Bachiller en Filosofía y Letras en el año académico 1865-66, con Literatura general españolas y Literatura clásica griegas y latinas, ambas con sobresaliente, obteniendo el Grado de Bachiller en Filosofía y Letras el 16 de marzo de 1867 con sobresaliente (AHN 6335/5). Siguió cursando los dos cursos siguientes en Granada, en 1866-67, con las asignaturas de Metafisica y ética y Lenguas árabes, $1^{\circ}$ curso, ambas con notable, Historia de España con sobresaliente. El último curso, 1867-68, 
cursó Literaturas españolas, Continuación de Historia de España y Lenguas árabes, $2^{\circ}$ curso, las tres con sobresaliente, obteniendo la Licenciatura el 5 de junio de 1868 (AHN 6335/5).

La carrera de Derecho la hizo también simultáneamente en Granada, aunque sus calificaciones son más bajas. El curso 1865-66 tuvo Derecho Romano. $2^{\circ}$ curso obteniendo un bueno y Derecho Civil español común y foral con un notable. Al año siguiente, 186667, Derecho Politico y Administrativo, $1^{\circ}$ curso con un notable y Derecho Canónico. $1^{\circ}$ curso con un bueno. En 1867-68, Elementos de Derecho Mercantil, Derecho Político y Administrativo, $2^{\circ}$ curso y Derecho $\mathrm{Ca}$ nónico, $2^{\circ}$ curso, las tres con un bueno, alcanzando el Grado de Bachiller en Derecho el 17 de junio de 1868 con nota de aprobado (AHN 3579/12).

Ya en Madrid desde fines de junio de 1868, continuó en la Universidad Central el quinto y último curso para obtener la Licenciatura en Derecho. Solicitó ingreso el 16 de septiembre de 1868, cursando las asignaturas de Ampliación de Derecho Civil y Códigos, Disciplina General Eclesiástica y Particular de España, Procedimientos judiciales y Prácticas forenses, todas con nota de aprobado. Pidió examen el 2 de junio, tocándole por sorteo el tema 88 , el capítulo $18 \mathrm{sec}$ ción 23 de Reformaciones, donde obtuvo un aprobado y el título de Licenciado en Derecho Civil y Canónico el 14 de junio de 1869 (AHN 3579/12), teniendo 20 años.

\section{INGRESO Y RÁPIDO CESE EN EL MUSEO ARQUEOLÓGICO NACIONAL}

El 16 de junio de 1868, ya licenciado en Filosofía y Letras en la Universidad de Granada con calificación de sobresaliente, presentó una instancia solicitando incorporarse a una de las plazas de ayudante "no provistas aún en el Museo Arqueológico Nacional”, siguiendo el Real Decreto de 12 de junio de 1867 que regulaba las vías para ingresar en el Cuerpo de Archiveros (AGA 31/06499)

Menos de 10 días después, el 25 de junio de 1868, fue nombrado por el Ministro de Fomento, Severo Catalina del Amo, Ayudante de Tercer Grado del Cuerpo de Archiveros, Bibliotecarios y Anticuarios con destino en el Museo Arqueológico Nacional, que dirigía su padre, Amador de los Ríos, donde tomó posesión el 30 de junio (AMAN EP RAR 1-2; Amador de los Ríos 1889: 5), con 19 años. Apenas 5 meses después, producida la revolución de septiembre de 1868 , fue cesado por el nuevo Ministro de Fomento, el 20 de noviembre de

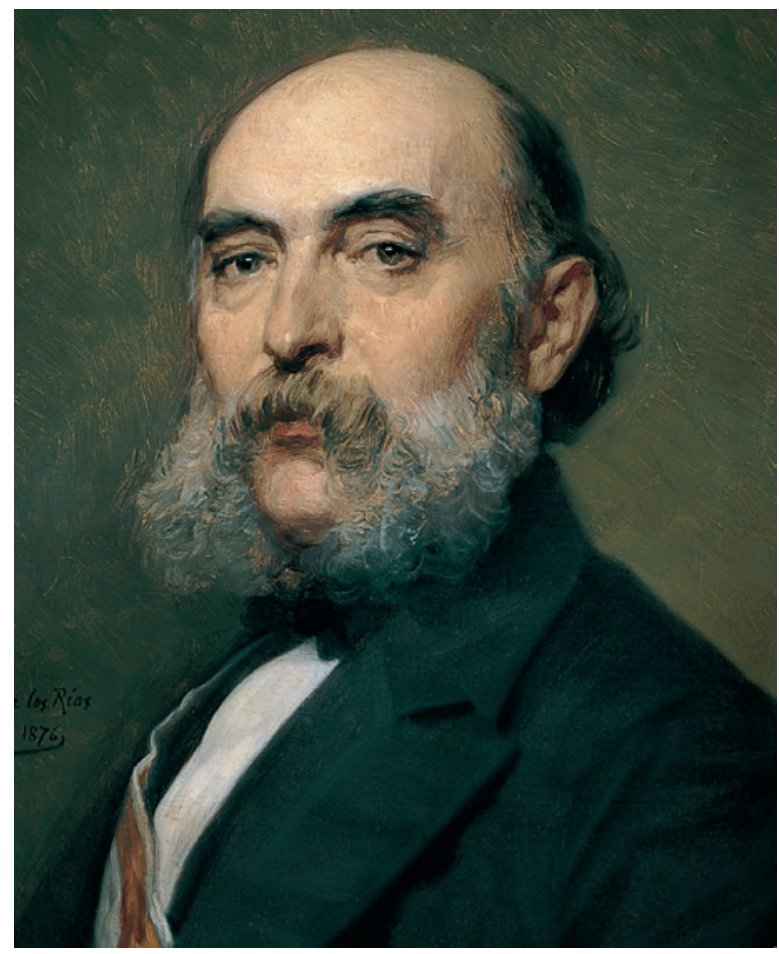

Figura 1. José Amador de los Ríos y Serrano, 1876. RABASF.

1868 (AMAN EP RAR 28; Amador de los Ríos 1889: 5 ), aunque se había sugerido el mes de octubre (Pasamar y Peiró 2002: 526).

Con 20 años fue sorteado en el reemplazo de 1869 por el distrito de Buenavista de Madrid, donde se le describe con pelo y ojos negros, barba y $1.62 \mathrm{~m}$. de altura, pero parece que el Ayuntamiento de Madrid cubrió en metálico el reemplazo y así "ninguno de sus hijos sería obligado al servicio de las armas" (AMAN EP RAR 18). No obstante, es probable que hiciese el servicio militar entre 1870-72, justo antes del estallido de la Tercera Guerra Carlista el 21 de abril de 1872, momento en que pudo ser también movilizado. Veinte años y grado de teniente señala en uno de sus relatos de ficción sobre la guerra (Amador de los Ríos, 1884a: 588), indicando que fue declarado útil para el servicio militar por el médico después de sacar el número 4 en el sorteo (Amador de los Ríos, 1884b: 117). Combatió en un batallón de cazadores (Amador de los Ríos, 1884b: 274), licenciándose con el grado de alférez (Amador de los Ríos, 1884c: 293). La barba la conservaba cuando ingresó, o reingresó, en el ejército en 1893, pues describe como su hija Elisa jugueteaba "con mis bigotes y mi barba, con la dorada chapa de la gola y los relucientes botones de mi guerrera" (Amador de los Ríos 1903a: 102). 


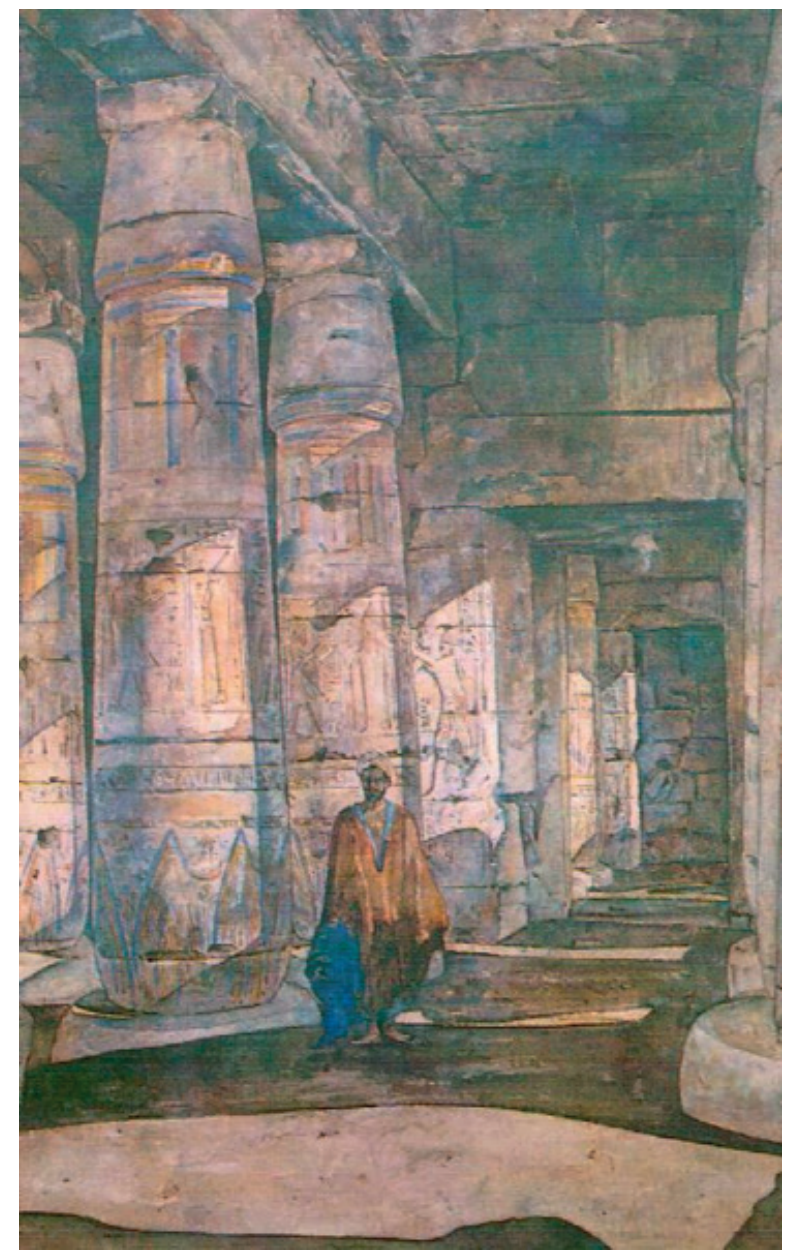

Figura 2. Ramiro Amador de los Ríos en el templo de Karnak (Egipto), 1876-77. Acuarela. Colección particular.

Después entró a trabajar en el bufete de José María Fernández de la Hoz Gómez durante el Sexenio Revolucionario (Anónimo 1916: 345), Ministro de Gracia y Justicia entre enero y junio de 1858, bajo la presidencia de Francisco Javier de Istúriz Montero. Durante la Restauración, Fernández de la Hoz inicialmente apoyó a Cánovas del Castillo, pero luego se incorporó al Partido Liberal Fusionista con el que fue Senador.

Otra actividad en el ámbito del derecho fue incorporarse como Profesor-Académico de la Real Academia de de Jurisprudencia y Legislación desde el 1 de mayo de 1872 (AGA 31/06499; AMAN EP RAR 39; Amador de los Ríos 1889: 9), fruto de lo cual acabó publicando un Proyecto de Ley de Propiedad Literaria (Amador de los Ríos 1878).

En 1874 se dividió en tres plazas la cátedra de Principios Generales de Literatura y Literatura Española en la Universidad Central de Madrid, lo que le permitió acceder a un puesto de auxiliar de cátedra con un sueldo similar al que había tenido en el Museo Arqueológico Nacional, 1.500 pesetas, el 28 de noviembre de 1874, pero apenas permaneció 9 meses porque con la reforma del profesorado auxiliar desaparecieron esos puestos el 31 de agosto de 1875 (AGA 31/06499; AMAN EP RAR 28).

Es posible que ello explique que realizase previamente los exámenes del Grado de Doctor en Filosofía y Letras que aprobó el 25 de junio de 1874, con el trabajo original de 65 páginas, Estudio histórico sobre Abú-Abdil-Láh Mohámmad $V$ de Granada y Don Pedro I de Castilla, como un requisito previo a presentarse a la plaza. El trabajo lo entregó el 12 de junio, siendo leído por un tribunal presidido por el catedrático de Hebreo, natural de Sevilla, Antonio María García Blanco, siendo secretario el entonces auxiliar de cátedra José Canalejas y Méndez, junto con Alfredo Adolfo Camús, catedrático de Literatura Griega y Latina, y Manuel María del Valle y Cárdenas, que leyeron el texto entre el 22 y 23 de junio, calificándolo de aprobado (AHN 6335/5).

En este periodo se ha sugerido que fue pensionado de la Academia de Bellas Artes de Roma durante el curso académico "1873-1874", siendo "el primer español que explora los monumentos del Alto Egipto y realiza un estudio sobre el templo de Luxor" (Pasamar y Peiró 2002: 525-526; Balmaseda 2009: 81), pero ya se ha señalado que la estancia fue realizada por su hermano, el arquitecto Ramiro Amador de los Ríos, "arquitecto pensionado en Roma por oposición" (Pavón 1978: 156) por tres años, que marchó a Egipto entre 1876-77 (López Grande 2004: 236-237) (fig. 2).

\section{REINCORPORACIÓN AL MUSEO ARQUEOLÓGICO NACIONAL Y PUBLICACIÓN DE LA MEMORIA ACERCA DE ALGUNAS INSCRIPCIONES ARÁBIGAS DE ESPAÑA Y PORTUGAL}

Sin embargo, poco antes, con el inicio de la Restauración, consiguió ser readmitido en su puesto como se hizo con otros previamente cesados (Mederos 2013: 200-202), y así el Director General de Instrucción Pública, Joaquín Maldonado, ordenó el 19 de marzo de 1875 su reingreso en el Cuerpo con un ascenso a Ayudante de Segundo Grado, que también suponía una subida de sueldo hasta 2.000 pesetas anuales, tomando posesión el 24 de marzo (AGA 31/06499; AMAN EP 
RAR 3 y 6; Amador de los Ríos 1889: 5), aunque se había apuntado el 12 de febrero (Pasamar y Peiró 2002: 526). Intentó años después, en febrero de 1881, una mejora en el escalafón reclamando por los años que estuvo cesante, pero el Consejo de Estado lo desestimó en marzo pues "equivaldría a declarar de servicio activo el tiempo en que estuvo cesante" (AGA 31/06499; AMAN EP RAR 32 y 34).

Ya desde 1872, con la aparición de la revista Museo Español de Antigüedades, Amador de los Ríos (1872, $1873,1874 \mathrm{a}$ y b) mostró su interés por el arte árabe en España publicando 4 notables trabajos, iniciando en 1874 sus estudios sobre epigrafía arábiga en Córdoba (Amador de los Ríos 1879: xxi), por lo que al reingresar en el Museo Arqueológico Nacional fue destinado en la Sección Segunda de Edades Media y Moderna, en las salas de arte hispano-mahometano y estilo mudéjar (AGA 31/06499; AMAN EP RAR 39). Siendo sólo Ayudante de Segundo Grado, y con menos de un año de ejercicio difícilmente podía haber reingresado como Jefe de la Sección Segunda según habían sugerido Pasamar y Peiró (2002: 526) o Balmaseda (2009: 81).

Estos "dos salones (...) estaban destinados al Arte hispano-mahometano y á su derivación cristiana del estilo mudéjar, propio y exclusivo de España" siendo "la que ha excitado y excita la atención sostenida de los extranjeros que visitan con ánimo de aprender nuestro Museo Arqueológico Nacional" (Amador de los Ríos 1903b: 55-56 y 1888: 375). No debe olvidarse que las ciudades de Granada, Córdoba o Sevilla en España eran la alternativa a un tour en el Mediterráneo Oriental de mayor coste y más difícil realización por la inestabilidad política debida al proceso de fragmentación del Imperio Otomano. Sin embargo, la exhibición se mostraba "en singular confusión mezclado, y sin que de la exposición (...) pudiera el visitante deducir las enseñanzas (...) que el Museo debía ofrecerle en ordenadas series, científicamente sistemáticas" (Amador de los Ríos 1903b: 58).

$\mathrm{Su}$ trayectoria investigadora le permitió presentar, apenas ingresó en el Museo Arqueológico Nacional, una instancia al Ministerio en 1875 para solicitar una comisión de 2 meses para el estudio de las inscripciones árabes de España y Portugal, que le concedió el director general, Joaquín Maldonado, el 8 de julio de 1875 , con una dotación de 2.500 pesetas para viajes, dietas y compra de piezas que salían del presupuesto de adquisiciones del MAN (AMAN EP RAR 10). Inició su viaje en comisión el 26 de julio, solicitando la prórroga de un mes más que le fue concedida el 27 de septiembre, reincorporándose el 26 de octubre (AMAN EP
RAR 10-11, 15-16), visitando las provincias de Sevilla, Córdoba, Granada, Málaga, Almería y Toledo (AMAN EP RAR 21). La prorroga seguramente estuvo relacionada con la finalización de su docencia en la Universidad Central, por la supresión de las plazas de auxiliares, que ya no hacían preciso que se reincorporara a las clases en octubre. El resultado se plasmó inmediatamente con la publicación de Inscripciones árabes de Sevilla (Amador de los Ríos 1875a), un libro de 270 páginas, con prólogo de su padre, José Amador de los Ríos, y su artículo sobre la Mezquita de Almanzor o iglesia de San Bartolomé en Córdoba (Amador de los Ríos 1875b). Como señalaba en su siguiente monografía, fue "nuestro señor Padre, quien tantas veces nos alentó en la empresa" de la epigrafía arábiga hispana (Amador de los Ríos 1879: xxviii).

La reanudación de esta comisión epigráfica la volvió a solicitar el 24 de marzo de 1877, para continuar el estudio en otras provincias, que se le concedió el 30 de junio, por 2 meses, con similar partida de 2.500 pesetas del presupuesto de adquisiciones del Museo Arqueológico Nacional. Partió el 20 de julio y se reincorporó el 20 de septiembre (AMAN EP RAR 21, 23, 25 y 27). Cabe presumir que resultado de este trabajo fue la publicación de Inscripciones árabes de Córdoba (Amador de los Ríos 1879), el cual ya en una hoja de servicios de 1878 indicaba que estaba en prensa (AMAN EP RAR 28). También completó el trabajo de su padre sobre $M o$ numentos Latino-Bizantinos de Córdoba (De los Ríos y Amador de los Ríos 1879), que apareció en dos volúmenes casi simultáneamente.

Estos años son los de su mayor productividad científica, con 2 artículos en el Museo Español de Antigüedades de 1875 (Amador de los Ríos 1875b y c); 2 en 1876 incluyendo las lápidas con inscripciones árabes del Museo Arqueológico Nacional y de la Real Academia de la Historia (Amador de los Ríos 1876a y b); 5 en 1877 sobre elementos de techumbre de la mezquita de Córdoba, una pila de la Alhambra de Granada o arquetas arábigas de plata y marfil del Museo Arqueológico Nacional (Amador de los Ríos 1877a-e); 6 en 1878 sobre lápidas arábigas del Museo Provincial de Córdoba, celada de Boabdil en la Armería Real, la Mezquita Aljama de Córdoba o una hoja de puerta mudéjar de la Catedral de Sevilla (Amador de los Ríos 1878a-f); 2 en 1880, pues la revista no se publicó en 1879 (Amador de los Ríos $1880 \mathrm{a}$ y b) y 2 en 1881, cuando desaparece la revista, incluyendo uno sobre quicialeras arábigas del Museo Arqueológico Nacional (Amador de los Ríos 1881a y b).

La publicación de la Memoria acerca de algunas inscripciones arábigas de España y Portugal (Amador 
de los Ríos 1883), resultado de sus comisiones de 1875 y 1877 , lo convierte en el mejor especialista español en inscripciones arábigas de la segunda mitad del siglo XIX, realizando un trabajo paralelo al que realizó Hübner (1869) con las inscripciones latinas. No debe olvidarse que las aportaciones en epigrafía arábiga de Gayangos (1848, 1851, 1852 y 1853) son pequeñas comparativamente y se interrumpen a mediados del siglo XIX, y en su libro, el propio Amador de los Ríos (1883: 7) no duda en criticar algunos errores de Gayangos, a veces ya "corregidas una y otra vez por el malogrado Lafuente y Alcántara" (1859) en sus Inscripciones árabes de Granada. Por otra parte, sus monografías también suponen que se había convertido en la figura más importante de la arqueología arábiga hispana, campo donde Gayangos realizó su última aportación con Principios elementales de la escritura arábiga a inicios de la década de los sesenta (Gayangos 1861). La dedicación de Rada a este campo fue ocasional, aunque con aportaciones interesantes como Las peregrinaciones a La Meca (Rada 1884/2005) o la publicación a su nombre del catálogo de monedas arábigas del Museo Arqueológico Nacional (Rada 1892) que recoge el trabajo de Vives y Codera. Es importante tenerlo en cuenta, puesto que Amador de los Ríos nunca accedió a la Real Academia de la Historia, y en cambio tuvo un gran peso académico Gayangos, quien vivió hasta 1897.

La Memoria acerca de algunas inscripciones arábigas de España y Portugal inicialmente pensó publicarla continuando sus libros sobre las inscripciones de Sevilla y Córdoba, en dos trabajos independientes que se llamarían Inscripciones árabes de Granada e Inscripciones árabes de Toledo, Mérida, Badajoz, Málaga, Almería, Murcia y Portugal según señala entre sus obras "próximas a publicarse" de su libro de Inscripciones árabes de Córdoba (Amador de los Ríos 1879), pero finalmente optó por publicarlas en un volumen único ${ }^{2}$.

El fallecimiento del responsable de la Sección Segunda del Museo Arqueológico Nacional y la ausencia en comisión de servicio de su sucesor, Paulino Saviron, le hizo responsable provisional de la Sección Segunda de Edades Media y Moderna del museo desde el 1 de julio

2. Incluye Córdoba (inscripciones $\left.n^{\circ} 1-10\right)$, Sevilla $\left(n^{\circ} 11-22\right)$, Jerez (Cádiz) (nº 23-25), Ceuta (n 26-30), Almería (nº 31-45), Málaga ( $\left.\mathrm{n}^{\circ} 46-48\right)$, Loja (Granada) $\left(\mathrm{n}^{\circ} 49\right)$, Granada $\left(\mathrm{n}^{\circ} 50-82\right)$, Murcia $\left(n^{\circ} 83-86\right)$, Játiva (Valencia) $\left(n^{\circ} 87-89\right)$, Valencia $\left(n^{\circ} 90-92\right)$, Toledo $\left(n^{\circ} 93-121\right)$, León ( $\left.n^{\circ} 122-123\right)$, Santander ( $\left.n^{\circ} 124\right)$, Mérida $\left(n^{\circ} 125\right.$ 142), Badajoz ( $\left.n^{\circ} 143-145\right)$, Lisboa ( $\left.{ }^{\circ} 146-150\right)$, Coimbra $\left(n^{\circ} 151\right)$, Braga ( $\left.n^{\circ} 152\right)$, Porcuna (Jaén) (n 153), Pamplona ( $\left.n^{\circ} 154\right)$ y Madrid $\left(n^{\circ} 155\right)$. de 1881 (AMAN EP RAR 39), que le fue encargada el 26 de marzo de 1888 al encontrarse el jefe de la sección en comisión fuera del museo (Amador de los Ríos 1889: 8). En la Sección Segunda permaneció hasta su nombramiento como director en 1911 (Anónimo 1916: 345).

\section{PROFESOR AUXILIAR EN LA UNIVERSIDAD CENTRAL DE MADRID}

A partir del curso 1882-83, Amador de los Ríos pudo reincorporarse como Auxiliar de la cátedra de Historia Crítica de España y de Literatura Española, desde el 11 de noviembre de 1882, y volvió a ser llamado para la cátedra de Literatura Española y Nociones de Literatura y bibliografía jurídica de España el 30 de enero de de 1884 (AGA 31/06499; AMAN EP RAR 30; Amador de los Ríos 1889: 6), hasta que a finales de ese año regularizó su situación alcanzando el puesto de Profesor Auxiliar de la Facultad de Filosofía y Letras, en la cátedra de Historia Crítica de España, siendo nombrado el 20 de noviembre de 1884, plaza de la que tomó posesión el 27 de noviembre, con un sueldo de 2.500 pesetas. Este dinero complementaba a las 3.000 pesetas que pasó a cobrar desde el mes de julio de 1884 cuando fue ascendido a Oficial de Tercer Grado en el Museo Arqueológico Nacional (AMAN EP RAR 45 y 50; Amador de los Ríos 1889: 6-7). La cátedra de Historia Crítica de España estaba detentada por Manuel Pedrayo y Valencia, quien la ocupó hasta su jubilación en 1894 (Gaceta de Instrucción Pública 6 (185), 5-61894: 1369). También desempeñó provisionalmente entre el 30 de octubre y el 24 de noviembre de 1885 la secretaría de la Facultad de Filosofía y Letras de la Universidad Central (Amador de los Ríos 1889: 8).

Aunque la muerte de su padre, el 17 de febrero de 1878 , le perjudicó, tuvo un importante valedor en su cuñado, Francisco Fernández y González, casado con su hermana Isabel Matilde Amador de los Ríos. Fue catedrático de Estética en el doctorado de Filosofía y Letras de la Universidad Central entre 1864-1903, donde llegó a ser Decano $(1879,1894)$ y finalmente Rector (1895-1903).

\section{AMPLIANDO SUS ESTUDIOS EN LA ESCUELA SUPERIOR DE DIPLOMÁTICA}

Rodrigo Amador de los Ríos había ingresado en el cuerpo en la fase inicial como licenciado, obteniendo luego el doctorado. Sin embargo, trabajando en el 
cuerpo de archiveros le convenía disponer también de la titulación de la Escuela Superior de Diplomática, que dirigía su compañero en el museo, Juan de Dios de la Rada y Delgado desde 1876.

Como contaba con el título de Doctor en Filosofía y Letras y era Ayudante de Segunda Clase, podía ser admitido a examen según Real Decreto de 15 de febrero de 1883. Por ello, en el curso 1883-84 se presentó a los exámenes de septiembre de 1884, obteniendo la calificación en todas de notable, lo que no deja de ser un poco extraño ya que eran 7 asignaturas, Latín de los tiempos medios y conocimiento de los romances lemosín y gallego por Vicente Vignau, Geografía antigua y de la Edad Media, especialmente de España por Miguel García Romero, Paleografía general y crítica por Jesús Muñoz y Rivero, Numismática y Epigrafía por Juan de Dios de la Rada, Arqueología y Bellas Artes por Juan Facundo Riaño, Bibliografía y ordenación de Bibliotecas por Toribio del Campillo e Historia de las Instituciones de España en la Edad Media por Eduardo de Hinojosa. El aprobado le permitió solicitar examinarse del Grado el 26 de septiembre. El examen consistía en el sorteo de un tema, dándole un día para preparárselo y defenderlo en el examen. Así el 29 de septiembre salió el tema 46, Numismática árabe española, sus divisiones, periodos que abarca cada una de ellas, sus caracteres, que por el contenido arabista le favorecía. El examen tuvo el primer ejercicio el 30 de septiembre y el segundo el 2 de octubre, obteniendo la calificación de aprobado por unanimidad, es decir, la nota mínima, con un tribunal presidido por Juan de Dios de la Rada como Director, Eduardo de Hinojosa como Secretario, Juan Facundo Riaño, Vicente Vignau y Ballester, Jesús Muñoz y Rivero y el profesor auxiliar Antonio Rodríguez Villa (AGUCM ED 17/61), si bien su título no fue expedido hasta el 9 de marzo de 1886 (AGUCM ED 17/61; AMAN EP RAR 50).

\section{ACADÉMICO DE LA REAL ACADEMIA DE BELLAS ARTES DE SAN FERNANDO}

Rodrigo Amador contaba con los mejores antecedentes para acceder a la Real Academia de Bellas Artes de San Fernando. Su padre, José Amador de los Ríos, había sido Académico de Número por Arquitectura entre 1859-78; su tío, Diego Manuel Amador de los Ríos fue Correspondiente por Granada entre 1866-71; otro tío, Demetrio de los Ríos, fue Correspondiente por Sevilla entre 1865-92; su hermano, el arquitecto Ramiro Amador de los Ríos, fue nombrado Correspondiente por Toledo el 11 de abril de 1870; y su cuñado, Francisco Fernández y González, fue elegido Académico de Número por Arquitectura el 24 de mayo de 1875, aunque no ingresó hasta el 12 de junio de 1881, hasta su muerte el 30 de junio de 1917.

Un elemento que debió pesar significativamente fue la publicación en un breve plazo de cuatro importantes monografías dentro de la colección España. Sus monumentos y artes. Su naturaleza é historia, primero Burgos (Amador de los Ríos 1888), luego Murcia y Albacete (Amador de los Ríos 1889; Zapata 2006), quizás elegidas porque Albacete era la provincia de nacimiento de su cuñado, Fernández y González y Murcia la de su mujer. Poco después, también redactó Huelva y Santander (Amador de los Ríos 1891a y b). La primera de ellas ya había sido objeto de su interés por la presencia de las murallas islámicas de Niebla con 46 torreones y varias puertas, "el único recinto amurallado que subsiste en España, de cuantos los muslimes construyeron para defensa de sus poblaciones" (Amador de los Ríos 1906b: 231), defendiendo en la Academia su importancia para que fuese declarado Monumento Nacional pero "Por desgracia, mi voz en aquella ocasión fue como la vox clamantis in deserto" (Amador de los Ríos 1906b: 232). Esta provincia la visitó en noviembre de 1890, durante la redacción de la monografía, destacando la iglesia mudéjar de San Jorge en Palos, con su Puerta de los Novios (Amador de los Ríos 1903c: 9599, 104). El trabajo de Santander lo dedicó a Marcelino Menéndez y Pelayo, al que consideraba "legítimo heredero del autor de la Historia Crítica de la Literatura Española (...) la cátedra de mi llorado Sr. padre" (Amador de los Ríos 1891b: v).

La dedicatoria a Menéndez y Pelayo sugiere que buscaba el apoyo de Menéndez y Pelayo por encabezar el Cuerpo de Archiveros y del ala neocatólica, en contraposición con el ala liberal que representaban Gayangos y Riaño. Por otra parte, también señalaba que Rodríguez de Berlanga era el "primero de nuestros epigrafistas romanos" (Amador de los Ríos 1912: 284), opinión que no le habría agradado en exceso al padre Fidel Fita, quien desde 1909 fue el Anticuario de la Real Academia de la Historia.

Estos trabajos condujeron a su elección como Académico de Número "en la clase de no profesores por la sección de pintura" el 27 de enero de 1890 (RABASF Libro Actas 3-100, 27-1-1890: 164), por fallecimiento el 4 de septiembre de 1889 del marqués de Molins, Mariano Roca de Togores.

Fue propuesto el 10 de noviembre de 1889 por el Bibliotecario y presidente de la sección de Pintura, 
Pedro de Madrazo; el pintor de temas históricos Dióscoro Teófilo Puebla Tolín, miembro de la sección de pintura; el escritor sevillano de teatro histórico, Manuel Cañete, también miembro de la sección de pintura; y el arquitecto Antonio Ruiz de Salces, quien había retomado la dirección de la construcción de la Biblioteca y Museo Arqueológico Nacional. Era entonces director Federico de Madrazo, quien fue reelegido poco después, el 30 de diciembre de 1889 (RABASF Libro Actas 3-100, 30-12-1889: 142). Pedro de Madrazo y Kuntz había sido propuesto por el padre de Rodrigo, José Amador de los Ríos, como Académico de la Historia en 1859. Por otra parte, Rodrigo Amador de los Ríos (1879: xxv) ya había resaltado la labor del "muy docto arqueólogo, Excmo. Sr. D. Pedro de Madrazo, á quien debe Córdoba el libro más completo que de ella se ha escrito". Su calificación como arqueólogo se debe a que Pedro de Madrazo y Pascual de Gayangos solicitaron en diciembre de 1853 excavar en Madinat al-Zahra', pero el propietario de los terrenos, el Marqués de Guadalcázar, no lo autorizó (Amador de los Ríos 1906a: 30). Manuel Cañete era por su origen sevillano e interés en el teatro español del siglo XVI una persona próxima a José Amador de los Ríos. En cambio, la relación de Amador de los Ríos (1903b: 60, 62) con Ruiz de Salces es más ambivalente, lo critica un poco por el edificio del museo, una "construcción, que resulta en su conjunto fría y algún tanto descompuesta”, pero considera que si Rada le hubiera reclamado una mejor distribución del espacio frente a las presiones del director de la Biblioteca Nacional, "seguro que éste habría dado solución, entonces satisfactoria y sin menoscabo ni perjuicio de nadie". También es interesante ver quiénes no firmaron la propuesta, entre los que cabe reseñar a Juan Facundo Riaño, Juan de Dios de la Rada y Delgado, ni tampoco su cuñado Francisco Fernández y González.

Fue la única propuesta presentada, cuyo plazo finalizó el 6 de enero de 1890, siendo discutida en la sesión del 13 de enero (RABASF Libro Actas 3-100, 13-11890: 146-147), que la trasladó a la sección de pintura, la cual presentó informe favorable en la sesión del 20 de enero (RABASF Libro Actas 3-130, 20-1-1890: $68 \mathrm{r}$ ), fijándose su votación para sesión extraordinaria del 27 de enero (RABASF Libro Actas 3-100, 20-11890: 149). La elección estuvo presidida por Pedro de Madrazo, pues el director estaba de baja por enfermedad, en votación secreta, aunque no se especifica el número de votos obtenidos entre los 21 miembros que asistieron (RABASF Libro Actas 3-100, 27-1-1890: 164), y Amador de los Ríos remitió su aceptación en la sesión del 3 de febrero (RABASF Libro Actas 3-100,
3-2-1890: 165). Realizó el discurso de ingreso el 17 de mayo de 1891, sobre Las pinturas de la Alhambra de Granada (Amador de los Ríos 1891c), que fue contestado por el compositor de zarzuelas Francisco Asenjo Barbieri, Académico de Número por Música desde el 17 de junio de 1875. Ya figuró por primera vez en reunión de la sesión ordinaria el 18 de mayo (RABASF Libro Actas 3-100, 28-5-1891: 421), donde se aprobó el acta de la junta pública del domingo 17 de mayo, con el acto de la recepción de Amador de los Ríos, y se incorporó como secretario de la sección de pintura desde el 6 de junio (RABASF Libro Actas 3-130, 6-6-1891: 77r).

\section{LAS EXPOSICIONES DEL CENTENARIO DEL DESCUBRIMIENTO DE AMÉRICA Y LA APERTURA DEL NUEVO MUSEO ARQUEOLÓGICO NACIONAL}

El interés por la museología de Amador de los Ríos se mantenía en 1887 cuando solicitó una Comisión gratuita para visitar los principales museos españoles el 19 de octubre de 1887 (AGA 31/06499). También comenzó a impartir un curso de Epigrafía arábigo-española en el Museo Arqueológico Nacional desde el 20 de octubre de 1888 (Amador de los Ríos 1889: 9). No obstante, comenzaban a manifestársele a los 39 años síntomas de reuma articular por la humedad dentro del museo, por lo que pidió en abril de 1888 un mes de baja para tratarse en las aguas del manantial de Alhama (Granada) (AMAN EP RAR 56-57).

La situación del Museo Arqueológico Nacional no era fácil por "la exigüidad de la dotación que le está asignada para adquisiciones, y con la cual es necesario atender á otras muchas exigencias de índole distinta, entre las cuales figuran las de reparación constante del local y la de construcción de aparatos; la rareza con que se verifican exploraciones á las provincias (...) y en odio á la centralización oponen activa resistencia al engrandecimiento del Museo Arqueológico Nacional", no remitiéndose muchos hallazgos arqueológicos importantes (Amador de los Ríos 1888: 377).

Sin embargo, la etapa que comenzó con la entrada como director en el Museo Arqueológico Nacional de Juan de Dios de la Rada y Delgado desde el 19 de febrero de 1891, supuso un cambio importante en su trayectoria. En teoría, según su expediente, todo parece normal, teniendo un ascenso a Oficial de Segundo Grado el 16 de febrero de 1889, con sueldo de 3.500 pesetas, un ascenso a Oficial de Primer Grado el 9 de diciembre de 1892 con sueldo de 4.000 pesetas y otro a 
Jefe de Tercer Grado el 1 de julio de 1895 (AMAN EP RAR 66-68). No obstante, no publicó ningún artículo en 1892 , lo que no era habitual y en 1893 presentó varios trabajos vinculados a Melilla (Amador de los Ríos 1893a-c), que hacen presumir que participó unos meses como voluntario en la guerra de Melilla o guerra de Margallo de 1893, por el nombre del Comandante General de Melilla, el general Juan García Margallo que falleció en el conflicto. Antes que combatiente, quizás marchó como intérprete de árabe en el ejército, como hizo el arabista Julián Ribera en 1894.

La marcha la podemos seguir por las Actas de la Comisión de Pintura de la Real Academia de Bellas Artes de San Fernando, donde siguió asistiendo hasta que fue sorteado para marchar a Melilla, ya que debía estar en la reserva, con 44 años. La última sesión a la que asistió fue el 7 de febrero de 1893 (RABASF Libro Actas 3-130, 7-2-1893: 92r), redactando en la siguiente reunión Domingo Martínez el acta y actuando Martínez Cubells como secretario accidental (RABASF Libro Actas 3-130, 11-4-1893: 93r). Ya figura de vuelta el 15 de junio (RABASF Libro Actas 3-130, 15-6-1893: 94r), y continuó en las sesiones del 24 de junio, 18 de octubre, 30 de octubre, 24 de noviembre, 8 de diciembre de 1893 (RABASF Libro Actas 3-130: 95r-99r), 17 de enero de 1894, 10 de marzo, 21 de marzo, 9 de mayo, 30 de mayo y 24 de junio (RABASF Libro Actas 3-130: 100r-106v), volviendo a no estar presente el 30 de junio siendo sustituido de nuevo por Martínez $\mathrm{Cu}$ bells como secretario accidental (RABASF Libro Actas 3-130, 30-6-1894: 107r), reincorporándose el 24 de octubre (RABASF Libro Actas 3-130, 24-10-1894: 107r).

Esta decisión la tomó Amador de los Ríos en un momento de intensa actividad dentro del museo, pues con motivo del IV Centenario del Descubrimiento de América se estaban preparando en el futuro museo del Paseo de Recoletos, denominado Palacio de Museos y Bibliotecas, la Exposición Histórico-Americana, dirigida por Juan Navarro Reverter, subsecretario de Hacienda y que había sido vicepresidente de la Exposición Universal de Barcelona, como delegado general ( $\mathrm{La}$ Ilustración Española y Americana, 22-9-1892: 174175) y Juan de Dios de la Rada y Delgado como delegado técnico. Fue inaugurada por la Reina Regente, María Cristina, el 11 de octubre de 1892, coincidiendo con el IX Congreso Internacional de Americanistas (La Rábida, Huelva, octubre 1892). También se preparaba la Exposición Histórico-Europea, que dirigía el padre Fidel Fita como delegado general y Catalina García como subdelegado general civil, inaugurada del 11 de noviembre de 1892 (La Ilustración Española y
Americana, 12-11-1892: 346-348), abierta hasta el 30 de junio de 1893. Al año siguiente se inauguró la Exposición Histórico-Natural y Etnográfica, refundición de ambas exposiciones, inaugurada el 4 de mayo de 1893, según Real Decreto de 25 de marzo, a lo que se sumó el inicio del trasvase de las restantes colecciones del $\mathrm{Mu}-$ seo Arqueológico Nacional desde su antigua sede en el Casino de la Reina, por Real Orden de 22 de julio de 1893, si bien no se inauguró hasta el 5 de julio de 1895 (Marcos Pous 1993: 73). No obstante, para "concurrir á aquel certamen [expositivo se] tuvo que atropellarlo todo, por la angustia del plazo, angustia ocasionada por no estar á su tiempo la obra del palacio concluida" (Amador de los Ríos 1903b: 62).

Podría pensarse que alguna decisión técnica de Rada, bien por su labor como responsable de la Sección Segunda del museo desde 1888, o más bien por su no participación en la organización de las exposiciones le llevasen a un cierto grado de distanciamiento. En este sentido, no deja de llamar la atención quienes colaboraron con Rada (1893: 180) en la Exposición HistóricoAmericana, cuyo delegado general fue nombrado desde el 24 de enero de 1891 (La Ilustración Española y Americana, 22-9-1892: 175), que incluían a José Ramón Mélida, Jefe de la Primera Sección de Protohistoria y Edad Antigua; Ángel de Gorostizaga y Carvajal, Jefe de la Sección de Etnografia; Eduardo de la Rada y Méndez, hijo de Rada, secretario del Museo Arqueológico Nacional; o Narciso Sentenach y Cabañas, que ingresó en el cuerpo en 1893 y al año siguiente fue trasladado al Museo Arqueológico Nacional a la Sección de Etnografía. Esto es, estaban casi todos los conservadores con responsabilidad en el museo, y sólo faltan Manuel Tomás Gil y Flores de la Sección Cuarta de Numismática y Glíptica y Amador de los Ríos de la Sección Segunda.

Sin embargo, la exposición a la que debía haber estado adscrito era a la Exposición Histórica-Europea, cuyo objetivo era mostrar la cultura de España y Portugal entre los siglos XV, XVI y primera mitad del siglo XVII, como Académico de Bellas Artes desde 1890 y Jefe de la Sección Segunda de Edades Media y Moderna del Museo Arqueológico Nacional, pero la presencia de un gobierno conservador presidido por Cánovas del Castillo entre el 5 de julio de 1890 y el 11 de diciembre de 1892, facilitó la promoción como subdelegado civil del conservador Catalina García, Catedrático de Arqueología en la Escuela Superior de Diplomática y Académico electo de Historia, aunque aún no había tomado posesión de la plaza hasta el 27 de mayo de 1894 (García y López 1894), cuya repercusión social se refleja en que fue la única vez en que Catalina 
García apareció retratado en La Ilustración Española y Americana (12-11-1892: 347-348).

Para asesorarle en la exposición para época islámica, Catalina García recurrió a Antonio Vives, que había sido contratado temporalmente en el Museo Arqueológico Nacional por Rada para redactar entre 1891-92 el Catálogo de monedas arábigas españolas que se conservan en el Museo Arqueológico $\mathrm{Na}$ cional (de la Rada, Vives y Codera, 1892). Ambos eran los principales rivales de Amador de los Ríos en el campo del arabismo. El aragonés Francisco Codera y Zaidín era desde 1874 el catedrático de Árabe de la Universidad de Madrid y su entrada en la Real Academia de la Historia el 20 de abril de 1879, hasta su muerte el 6 de noviembre de 1917, supuso un importante veto para la posible entrada de Amador de los Ríos. Ambos polemizaron por la interpretación de unos epígrafes árabes de la capilla de Santa Catalina de Toledo (Codera, 1894), al reinterpretarla Amador de los Ríos (1895a) una vez ingresó la pieza en el Museo Arqueológico Nacional. Puesto en evidencia Codera (1895) por Amador de los Ríos (1895b: 104), porque confundía la escritura nesji literaria con la escritura monumental cúfica que se usaba en el epígrafe. Como le recordaba públicamente Amador de los Ríos (1895b: 106), "Nadie debe hacerse (...) la ilusión de que ningún ramo de la ciencia sea patrimonio exclusivo suyo, ni de que sus obras se hallan exentas de error ó descuido, ni de que es infalible; porque los que para el público escriben, lo hacen para ser por el público libremente juzgados, y sienta mejor la modestia en el sabio que el desvanecimiento y la soberbia". No se lo perdonó Codera, quien pocos años después fue el principal impulsor con Saavedra para la elección de Vives como Académico de la Historia en noviembre de 1899.

A ello se sumó su profunda irritación por lo acontecido por el traslado del museo. A su juicio, la reorganización del espacio del edificio para beneficiar la Biblioteca Nacional supuso que "División tan arbitraria, impuesta por conveniencias particulares y personales (...) y apadrinada por altas influencias que la autorizaron, obligó desde luego a seccionar el Museo, perjudicando sobre modo la instalación de éste, y perturbando su unidad, así como los intereses científicos por él representados" (Amador de los Ríos 1903b: 61). Así pues, "destruida (...) la unidad superior científica del Museo, trató desde luego de obtener de aquellos locales el mejor partido posible el Sr. Rada y Delgado, conformándose á la fuerza con la distribución impuesta, según la cual, se proclamaba solemne y oficialmente la errónea afirmación de que Establecimientos de tal índole no crecen" (Amador de los Ríos 1903b: 63).

Uno de las primeras consecuencias fue que "los patios cubiertos de cristales, y para desahogo y ventilación abiertos, se convirtiesen forzosamente en salones de exposición; de que departamentos secundarios, sin luz ni condiciones, tuvieran que ser utilizados (...) y principalmente, por último, de que no fuera en modo alguno realizable la exposición sistemática y científica, que tanto y tan repetidas veces habían de menos echado en el antiguo local del Casino de la Reina" (Amador de los Ríos 1903b: 61-62).

Su Sección Segunda quedó situada en "El ala de la izquierda, que da á la calle de Villanueva (...) con los monumentos de la Edad Media y de la Edad Moderna, y con sus dos manifestaciones de arte cristiano y arte mahometano, en seis salones y el otro patio cubierto (...) cuya amplitud parecía consentir (...) pero por desdicha no lo permitía la construcción del patio (...) de cristales sobre altas columnas de fundido hierro (...) y prescindiendo de mayores detalles, échase de ver el desorden que reina en la exposición" (Amador de los Ríos 1903b: 63-66).

Además, "para cada siete salones no hay sino dos porteros, quienes ni pueden todos los días proceder a la limpieza (...) ni ejercer la debida vigilancia con los visitantes (...) Por otra parte, las corrientes son en el invierno tales, que los cristales de las vitrinas (...) se rajan (...) en los Patios el sol en el verano destruye los colores de las telas (....) despega las piezas de cerámica recompuestas (...) y en el invierno, el agua penetra y acaba con lo que respeta el calor en el verano. El papel pintado que reviste los muros, salta resquebrajado y roto $(. .$.$) y por tanto que las aguas pluviales siguen re-$ zumándose en los muros de la caja de la escalera; los patios y otros salones presentan manchas y jirones en el papel" (Amador de los Ríos 1903b: 67-68).

"La premura con que fue terminada la obra del $\mathrm{Pa}-$ lacio en 1892, privó á ésta de los medios de calefacción indispensables para que el público (...) pueda visitar el Establecimiento (...) siendo imposible en invierno transitar por los salones, lo uno, por el frío, lo otro, por las corrientes de aire, las cuales podían haber sido evitadas con canceles ó cortinones en las puertas (...) habiendo enfermado allí individuos del personal facultativo y del administrativo" (Amador de los Ríos 1903b: 69), incluido el propio Amador.

Un escrito autobiográfico de Amador de los Ríos (1903: 102) da algunas pistas de que sucedió. Parece que había ingresado en la Academia militar, “desde que salí de la Academia, allá estuve con mi 
regimiento batiendo a los carlistas en el Norte y sólo había sacado ligero rasguño", comentario que parece más propio de la Tercera Guerra Carlista (1872-76) en la que murió su hermano Alfonso. Indica que salió por sorteo para ir a la "última expedición á Melilla (1893)" contra "los salvajes rifeños", que debió ser entre febrero y junio cuando estuvo ausente de Madrid. La otra opción sería entre julio y septiembre, periodo en el que no hubo reunión. En el texto hace referencia a su mujer, Petra Cabezón Miranda, a la que llama "mi pobre María, sola, abandonada, triste, llorando sobresaltada en aquella pequeña habitación que había sido el nido feliz de nuestro amores (...) sólo dijo: ¡Sea lo que Dios quiera!...¡ Cumple con tu obligación", y a su hija Elisa Amador de los Ríos y Cabezón, entonces con 5 años, “mi pequeña Elisa, que iba reponiéndose de la enfermedad pasada del verano", estando su mujer embarazada de Alfonso Amador de los Ríos y Cabezón, "Me acordaba también de que María estaba en cinta", hijo al que le puso el nombre de su hermano fallecido en la guerra carlista. También menciona su traslado hacia Melilla, "el banquete de Córdoba, el recibimiento de Málaga (...) la ensenada de Melilla".

El conflicto surgió en 1893 por la construcción de un nuevo fuerte del sistema defensivo de la ciudad, el de Sidi Guariach Alto o de la Purísima Concepción, por su proximidad a un morabito y a un cementerio musulmán en sus inmediaciones. Después de varias escaramuzas durante la primavera y el verano de 1893, que se cobró alguna víctima española, cuando estuvo Amador de los Ríos. El conflicto estalló con un ataque completo al fuerte el 2 de octubre de 1893, muriendo o quedando heridos 13 soldados y trabajadores, siendo mutilados los cadáveres y los heridos finalmente ajusticiados, que al canjearse los cadáveres el 3 de octubre generaron notable polémica en España. Finalmente, unos 3.000 hombres y 3 baterías se desplazaron a Melilla desembarcando el 8 de octubre, frente a unos 9.000 rifeños. La batalla principal se desarrolló entre el 27 y 28 de octubre, día en que murió el general Margallo, y la situación no empezó a estabilizarse hasta la llegada el 28 de noviembre del general Arsenio Martínez Campos, con nuevas tropas que alcanzaron los 22.000 soldados, conformando el Ejército del Norte de África. No se retomaron las obras del fuerte hasta el 1 de diciembre. La paz se firmó con el Sultán de Marruecos, Hassan I, el 5 de marzo de 1894, fallecido pocos meses después, el 7 de junio, y entre marzo y septiembre las tropas fueron repatriadas (Rodríguez González 2008).

\section{LA VISIÓN NACIONALISTA ESPAÑOLA DEL MUNDO ISLÁMICO DE AMADOR DE LOS RÍOS}

Los textos sobre Melilla son interesantes porque reflejan su visión sobre el territorio norteafricano dentro de la corriente africanista imperante en la época. Sigue en parte la línea de su catedrático de árabe en la Universidad de Granada, el malagueño Francisco Javier Simonet y Baca, catedrático entre el 18 de enero de 1862 hasta su muerte el 9 de julio de 1897, con el cual se formó como arabista entre 1866-68, durante dos cursos académicos (AHN 6335/5), y al que recuerda como "mi antiguo maestro de lengua arábiga" (Amador de los Ríos 1906a: 40), caracterizado por su ideología carlista, defensor de un "integrismo" españolista y "ferviente católico" (Almagro 1904: 73-82).

Como profesor, Simonet no fue muy valorado por Gómez-Moreno (1952/1972: 15), quien señalaba que “el árabe (...) lo enseñaba Simonet; es decir, no lo enseñaba, sino que tomaba la lección uno a uno sobre apuntes suyos, y daba nota según lo que se había traducido de la Crestomatía" arábigo-española, con un vocabulario arábigo-español (Simonet y Lerchundi 1883).

A su juicio, la conquista de Melilla es "Testimonio y prueba de la aspiración constante sentida en España en todos [los] tiempos hacia la reintegración absoluta de lo que fue territorio suyo en otras edades, y expresivos representantes de su expansión nacional, una vez terminada en la conquista del reino granadino la gloriosa guerra de la Reconquista cristiana". Los sucesos de 1893 "proclaman, por desventura, la afrentosa decadencia á que somos llegados" (Amador de los Ríos 1893a: 262). En cambio, de haberse continuado la conquista de Melilla en el siglo XV, "hubieran dado como consecuencia la del territorio marroquí, contribuyendo por tanto al engrandecimiento de la Península" (Amador de los Ríos 1893a: 262).

Por otra parte, "en el presente siglo [XIX] han sido tan frecuentes como en los anteriores las agresiones de las cábilas, quienes gozan de grande independencia respecto del Sultán de Marruecos, cuyas órdenes no acatan, según ocurre en estos días, a despecho del tratado de Guad-Ras, y quienes aprovechan el menor pretexto para hostilizar la guarnición de la plaza [de Melilla], obligando a España a pensar seriamente en el formal y definitivo escarmiento de aquellas hordas salvajes" (Amador de los Ríos 1893c: 319).

Pocos años antes, el propio Amador de los Ríos (1891b: vi-vii) se definía como "español, todo lo más español que pueda imaginarse" frente al "fatal espectro 
del regionalismo". Estas críticas se vierten también en el Catálogo Monumental de Barcelona, en particular a algunas interpretaciones de los trabajos sobre el románico catalán del arquitecto y catedrático de la Escuela de Arquitectura en Barcelona, Josep Puig y Cadafalch, miembro del Institut d'Estudis Catalans, concejal de la Lliga Regionalista en el Ayuntamiento de Barcelona (1901-06), diputado en Cortes por Solidaritat Catalana (1907-09), diputado provincial por la Lliga Regionalista desde 1913, y partidario de una constitución federal para España. Según Amador de los Ríos (1913: 6 y 10) se estaba produciendo "el resurgimiento en el antiguo Principado, de cierto espíritu de exclusivismo separatista y de superioridad con relación á las restantes regiones y provincias españolas" pues "Todo parece estar hoy para ellos en Cataluña, y á Cataluña circunscripto y limitado. Nada hay en el resto de España que les interese". En otras ocasiones es más mesurado cuando habla de "la Patria, una, única é indivisible, pero varia y armónica sobre todo" (Amador de los Ríos 1903b: 42).

En todo caso, no debe olvidarse que Amador de los Ríos (1883: 4) rechaza tanto la expulsión de los moriscos, autores del arte mudéjar, como la de los judíos, "el desacertado edicto de Felipe III, expulsando de España las reliquias de la grey islamita, aun convertida bajo el peso de los acontecimientos (...) con igual intemperancia religiosa el de 1492 respecto de los hebreos". Además, considera que "la grey muslímica" contó con una "participación notabilísima que tuvo en el desarrollo de la cultura ibérica, de la eficacia con que intervino en la formación y génesis del carácter nacional, borrando entre los españoles antiguas diferencias de origen" (Amador de los Ríos 1888: 376).

\section{EL CONFLICTO POR LA APROBACIÓN DEL CATÁLOGO MONUMENTAL DE ESPAÑA}

La crisis del 1898 supuso la salida del gobierno el 4 de marzo de 1899 del liberal Práxedes Mateo-Sagasta Escolar, regresando los conservadores al poder, que habían perdido el gobierno desde el 4 de octubre de 1897, a raíz del asesinato de Cánovas del Castillo el 8 de agosto. El nuevo líder de los conservadores fue Francisco Silvela y de le Vielleuze, quien situó a Luis Pidal y Mon, II Marqués de Pidal, como Ministro de Fomento hasta el 18 de abril de 1900.

Dentro de una serie de medidas regeneracionistas, una de ellas fue empezar a elaborar un Catálogo Monumental de España, que pretendía evitar la exportación incontrolada de bienes muebles de España, en particular desde los pueblos pequeños, según sugerencia de Juan Facundo Riaño, director de la Real Academia de la Bellas Artes de San Fernando al ministro, "la idea era de don Juan; así se lo contó a mi padre confidencialmente doña Emilia" Gayangos (Gómez-Moreno Rodríguez 1991: 10).

Para elaborar el primer catálogo eligió a Manuel Gómez-Moreno Martínez, pues pensaba encargar primero Granada, su provincia de nacimiento, pero Gómez-Moreno le sugirió Ávila (Gómez-Moreno Rodríguez 1991: 13), para evitar suspicacias por la relación de Riaño con su padre, Manuel Gómez-Moreno González.

Para conseguir un nombramiento directo de Gómez-Moreno, Riaño intentó que fuera una propuesta de la Comisión Mixta organizadora de las Comisiones Provinciales de Monumentos, con representantes de las academias de Bellas Artes de San Fernando y de la Historia, sin pasar por ambas academias, pero "al redactar el proyecto correspondiente, se utilizó papel con el membrete de la Academia de San Fernando sobre el de la Comisión Mixta, por tener ésta allí su residencia oficial; al redactar el Ministro la Real Orden, omitió el segundo membrete, por lo que salió en la Gaceta como propuesta de la Academia [de Bellas Artes], sin figurar para nada el nombre de la Comisión” Mixta, según recoge Gómez-Moreno Rodríguez (1991: 11).

El conflicto adquirió mayor complejidad cuando se produjo una reorganización ministerial el 18 de abril de 1900 por parte de Silvela, quien dividió el Ministerio de Fomento, creándose un Ministerio de Agricultura, Industria, Comercio y Obras Públicas, a cargo de Rafael Gasset Chinchilla y un Ministerio de Instrucción Pública y Bellas Artes, antes una Dirección General, a cargo del diputado murciano, Antonio García Alix.

La Real Orden levantó notable resistencia en la Real Academia de Bellas Artes que "se alzó en pleno contra su director al que acusó de utilizar el nombre de la Academia sin consultarle y designar para el cargo a persona ajena a ella y desconocida. Capitaneaban la protesta Rada y Delgado y Amador de los Ríos" (Gómez-Moreno Rodríguez 1991: 11).

La discusión se puede seguir en las Actas de Sesiones de la Real Academia de Bellas Artes de San Fernando. El problema fue sacado a discusión casi desde el comienzo de la sesión por "El Sr. Amador de los Ríos [quien] pidió que se hiciera constar en el acta que él había dicho que la Comisión mixta organizadora se había extralimitado al proponer la persona que había de nombrarse para la formación del Catálogo monumental y artístico. El Sr. Presidente dijo que la Comisión se 
ha limitado á responder á la Real orden del Ministro pidiendo su informe. El Sr. Amador de los Ríos sostuvo su criterio de que se ha resuelto un asunto sin conocimiento de la Academia" (RABASF Libro Actas 3-104, 11-6-1900: 35).

El tema comenzó a tratarse de nuevo como segundo punto de debate que culminó con la solicitud de un voto de censura por parte de Amador de los Ríos por no ajustarse a los estatutos a la Comisión, e indirectamente a Riaño como miembro de la Comisión y director de la Academia. "De una Real orden expedida por el Exmo. Sr. Ministro de Instrucción pública y Bellas Artes, nombrando á D. Manuel Gómez Moreno para la formación del Catálogo monumental y artístico de la Nación (...) El Sr. Presidente dió explicaciones exponiendo como han sucedido los hechos (...) obedeciendo los deseos del Sr. Ministro (...) El Sr. Esperanza y Sola manifestó que si hay alguna equivocación, esta es del Ministro ó de los que han redactado la Real orden. El Sr. Amador de los Ríos dijo que se está fuera del Reglamento, leyó algunos artículos del mismo y dijo que los individuos de la Comisión se han extralimitado de sus atribuciones y censuró sus actos (...) El Sr. Amador de los Ríos manifestó que la culpable era la Comisión organizadora que no dijo al Ministro que no estaba en sus atribuciones el emitir dicho dictamen y propuso un voto de censura para la misma". Frente a este voto de censura, "El Sr. Fernández Duro (...) dijo que son dos cuestiones distintas y que deben tratarse por separado; una el error cometido sin duda alguna por la creencia de que la Comisión organizadora representa á las dos Academias y otra el voto de censura que desea se discuta separadamente" (RABASF Libro Actas 3-104, 11-6-1900: 35 38).

La otra voz crítica fue la de Rada y Delgado que consideró "incalificable" que se hubiese intentado engañar al Ministro argumentando un conocimiento por la Academia cuando previamente no se había tratado el tema, proponiendo nombrar una Comisión que visitase al Ministro para explicárselo. "El Sr. Rada dijo que debe hacer notar que hay un error en el hecho, que alguien ha podido hacer que pase el dictamen como emitido por la Academia, no siendo así, pareciéndole incalificable este proceder; que opina se debe dirigir la Academia al Sr. Ministro exponiéndole los hechos y que conste en las actas el error cometido. Dijo también que le extrañaba se hiciera mención del informe de catálogos del siglo último y no se mencionen hechos y trabajos recientes importantísimos. El Sr. Presidente dijo que reconocía el error que aparece en la Real orden y que está conforme en que se corrija en la forma en que la Academia acuerde; en cuanto á lo dicho por el Sr. Rada sobre los Catálogos, lo explicó diciendo que se ha dicho tratándolo en sentido general y no particular (...) El Sr. Rada propuso se nombre una Comisión que visite al Sr. Ministro, mejor que dirigirle una comunicación y la Academia acordó que una Comisión conferencie sobre el particular presentándole al propio tiempo una exposición (...) y fueron designados para formar la comisión los Srs. Rada y Delgado, Avalos, Álvarez y Capra, Fernández Duro y Salvador y Rodrigáñez acordándose también que la comunicación la redacte el Sr. Rada en unión del Secretario General", Simeón Avalos (RABASF Libro Actas 3-104, 11-6-1900: 36-38).

La situación la consiguió reconducir Riaño, con el apoyo de Eduardo Saavedra, al confirmar el nuevo ministro García Alix, que el Catálogo Monumental no fuese coordinado por la Real Academia de la Bellas Artes de San Fernando, sino por la Comisión Mixta organizadora de las Provinciales de Monumentos que presidía Saavedra, en la que también participaba Riaño, ratificando lo que había autorizado el Marqués de Pidal (Gómez-Moreno Martínez 1951-58/1977: 57; GómezMoreno Rodríguez 1995: 114-115).

El 18 de junio, antes de que la Comisión elegida por la Real Academia de Bellas Artes de San Fernando pudiese haber trasmitido su documento al Ministro, los académicos se encontraron con una nueva Real Orden. Amador de los Ríos volvió a esgrimir la falta de competencias de la Comisión y la necesidad de explicárselo al Ministro. "De una Real orden expedida por el Exmo. Sr. Ministro de Instrucción pública y Bellas Artes disponiendo que para acabar las dudas que haya podido suscitar el texto del Real Decreto del día 2 del corriente mes referente á la formación del Catálogo monumental de la Nación, sea la Comisión mixta organizadora de las provinciales de Monumentos la que emita los informes que aquel Ministerio crea procedentes sobre este asunto (...) El Sr. Amador de los Ríos manifestó su sorpresa por la lectura de la Real Orden (...) é hizo consideraciones acerca de la desairada situación en que quedaba este Cuerpo artístico, insistiendo en que debía hacerse algo que hiciera conocer al Ministro el sentimiento de la Academia. El Sr. Presidente [Riaño] defendió la autoridad de la Comisión organizadora para responder á una disposición ministerial para lo cual no debía considerarse incompetente (...) El Sr. Amador de los Ríos declaró que la Comisión organizadora no tiene atribuciones para entender en este asunto que se discute y al efecto explicó las atribuciones de las Secciones de la Academia y las de la Comisión Organizadora y pidió se haga algo que saque á la Corporación de la tristísima 
situación en que queda con este motivo" (RABASF Libro Actas 3-104, 18-6-1900: 41-43).

Por su parte, Rada esgrimió que ya se había redactado el escrito para el Ministro y solicitó leerlo en público, que parece haber recibido el apoyo de 23 de los 26 miembros de la Academia, pues sólo se manifestaron en contra Riaño, Fernández Duro y Ferrant, apoyando el escrito Fernández y González, Rada, Amador de los Ríos, Velázquez Bosco, José Ramón Mélida, Arturo Mélida o Avalos, entre otros. "El Sr. Rada y Delgado dijo que la Comisión nombrada para redactar la comunicación que ha de elevarse al Exmo. Sr. Ministro de Instrucción pública y Bellas Artes había cumplido su encargo y pidió se diera lectura de la misma para que sirviera de base de acuerdo á la Academia. El Sr. Presidente [Riaño] manifestó que no sabía hasta que punto sería ó no pertinente dicha comunicación después de la Real orden leída en la presente sesión, pero que entendía debía leerse el trabajo de la Comisión (...) El Sr. Fernández Duro pidió se le exima de formar parte de la Comisión que ha de visitar al Ministro por no encontrarse conforme con la exposición leída. El Sr. Ferrant une su voto á lo expuesto por el Sr. Fernández Duro" (RABASF Libro Actas 3-104, 18-6-1900: 43). Sin embargo, aunque la entrevista se celebró poco antes del 25 de junio de 1900 (RABASF Libro Actas 3-104, 25-6-1900: 52), el Ministro no modificó nada de su Real Orden.

\section{DIRECCIÓN DEL MUSEO ARQUEOLÓGICO NACIONAL}

La crisis del Catálogo Monumental irritó suficientemente al nuevo Ministro, García Alix, puesto que ponía en discusión una medida de su predecesor, el Marqués de Pidal, tomada bajo el mismo Presidente del Consejo, el conservador Francisco Silvela, y creemos que desencadenó la caída de Rada de director del Museo Arqueológico Nacional, que había sido senador varias veces con el partido liberal de Sagasta, y el ascenso de Catalina García a costa también de Amador de los Ríos. El Ministerio de Instrucción Pública solicitó el 24 de julio de 1900, “con carácter reservado y a la mayor urgencia" al Gobernador Civil de Almería, sus posibles partidas de bautismo entre 1823-30 (Papí 2004: 253), pues no estaba claro en qué año había nacido. Si era del año 1825, tenía entonces 74 años. Si había nacido en 1827 tenía 72 años y si era de 1829, tenía 71 años. Difícilmente es una coincidencia que la consulta del ministerio se realizase 4 días después de haberse suprimido la Escuela Superior de Diplomática del 20 de julio, el decreto del Catálogo Monumental de España se había firmado el 1 de junio y la visita al Ministro con el escrito crítico sobre la Real Orden, redactado por Rada y Avalos, se lo habían entregado poco antes del 25 de junio. Por otra parte, el Ministro de Fomento precedente había sido el neocatólico Luis Pidal y Mon, hermano de Alejandro Pidal, la persona clave en la promoción científica de su correligionario de partido, Catalina García. Pidal había sido la otra alternativa con Silvela para presidir el Partido Liberal-Conservador al morir Cánovas del Castillo, y es presumible la intención por parte de García Alix de reubicarlo adecuadamente.

El traslado de Catalina García al Museo Arqueológico Nacional el 29 de julio de 1900, con categoría de "Jefe de Primer Grado del Cuerpo" y su ascenso a Inspector de Tercer Grado y Jefe de Administración Civil de Tercera Clase menos de una semana después, el 4 de agosto (AGA 31/6520/54; AMAN EP CGL 1-2), el mismo día que se jubilaba a Rada y Delgado como director y 5 días antes de su toma de posesión (AMAN EP CGL 5), permitió su elección como director del museo. Su traslado debió frustrar las posibles aspiraciones al puesto de Amador de los Ríos, que aún seguía siendo Jefe de Tercer Grado desde 1895 y sólo pasó a Jefe de Segundo Grado el 11 de junio de 1901 (AMAN EP RAR 69). No debe olvidarse que tanto Catalina García como Amador de los Ríos acabaron sus estudios en Filosofía y Letras el mismo curso de 1867-68 y Amador de los Ríos finalizó un año antes los de Derecho el curso 1868-69, continuándolos Catalina García hasta 1869-70, si bien Amador de los Ríos era cuatro años más joven.

También llama la atención que durante los veranos de 1901 y 1902, Amador de los Ríos fuese enviado en comisión a ayudar en la catalogación del Archivo General Central de Alcalá de Henares. En 1901 durante los meses de mitad de agosto y septiembre, según escrito de 12 de agosto, y en 1902, según escrito del 19 de junio, fue trasladado entre julio y septiembre (AMAN EP RAR 71 y 73). Esto hizo que cuando solicitó Catalina García un permiso en julio de 1902, por estar comenzando a elaborar el Catálogo Monumental de Guadalajara que se le había encargado desde el 1 de febrero de 1902, fuera sustituido genéricamente por "el empleado de más categoría" (AGA 31/6520/54).

En todo caso, debió primar la prudencia en Rodrigo Amador de los Ríos puesto que Catalina García era por entonces profesor de su hijo, Alfonso Amador de los Ríos y Cabezón, impartiéndole el curso 1902-03 las asignaturas de Arqueología con calificación de notable y Numismática y Epigrafía con la nota de aprobado (AHN 6335/4). 
En cambio, a partir de 1904, se observa normalidad, siendo siempre Catalina García sustituido por Amador de los Ríos, primero en diciembre de 1904 cuando marchó a visitar los archivos de Soria y Guadalajara; a continuación en julio de 1905 cuando estuvo en Guadalajara elaborando el Catálogo Monumental; y posteriormente en julio de 1906 y en julio de 1907 cuando marchó a las excavaciones de Numancia y después a continuar el Catálogo Monumental de Guadalajara (AGA 31/6520/54), poco después de haber entregado el primer borrador del Catálogo el 26 de junio de 1906.

A pesar de que Amador de los Ríos partía con la ventaja de que su padre ya había sido Académico de $\mathrm{Nu}$ mero de la Real Academia de la Historia entre 1848-78, durante 30 años, resulta evidente que Catalina García, Académico de Número desde 1894, aunque propuesto desde 1890, y nada menos que Secretario Perpetuo desde diciembre de 1908, no tuvo interés en promocionar a Amador de los Ríos, su lógico sucesor por antigüedad en el escalafón del museo, lo que sí hizo con otro miembro del museo, Manuel Pérez-Villamil, de su misma provincia e ideología conservadora, cuyo discurso de recepción leyó en 1907 (Pérez-Villamil 1907). Tampoco parece haberlo hecho Rada y Delgado antes de su muerte en 1901, que había sido el encargado del discurso necrológico de José Amador de los Ríos y era compañero suyo en la Real Academia de Bellas Artes de San Fernando, quizás por veto de algún académico.

En todo caso, Amador de los Ríos alcanzó el 11 de junio de 1901 el nivel de Jefe de Segundo Grado (AMAN EP RAR 69), el 30 de mayo de 1905 fue ascendido a Jefe de Primer Grado con categoría de Jefe de Administración Civil de Cuarta Clase (AMAN EP RAR 75) y poco antes de la muerte de Catalina García, el 14 de enero de 1911, a Jefe de Administración Civil de Tercera Clase (AMAN EP RAR 77), siendo el propio Amador de los Ríos quien comunicó el 19 de enero el fallecimiento de Catalina García, firmando ya como director (AGA 31/6520/54) (fig. 3).

En febrero de 1911, vacante una plaza de Jefe de Administración Civil de Segunda Clase por ascenso de Antonio Rodríguez Villa, y probablemente en compensación por las reclamaciones previas de reconocimiento de antigüedad desde 1881 de Amador de los Ríos durante su cese entre 1868-75, fue ascendido el 12 de febrero, con sueldo de 8.750 pesetas (AMAN EP RAR 79) y finalmente el 8 de enero de 1915, alcanzo la categoría de Jefe de Administración Civil de Primera Clase e Inspector Primero de Administración Civil de Primera Clase, con sueldo de 10.000 pesetas (AGA 31/06499).

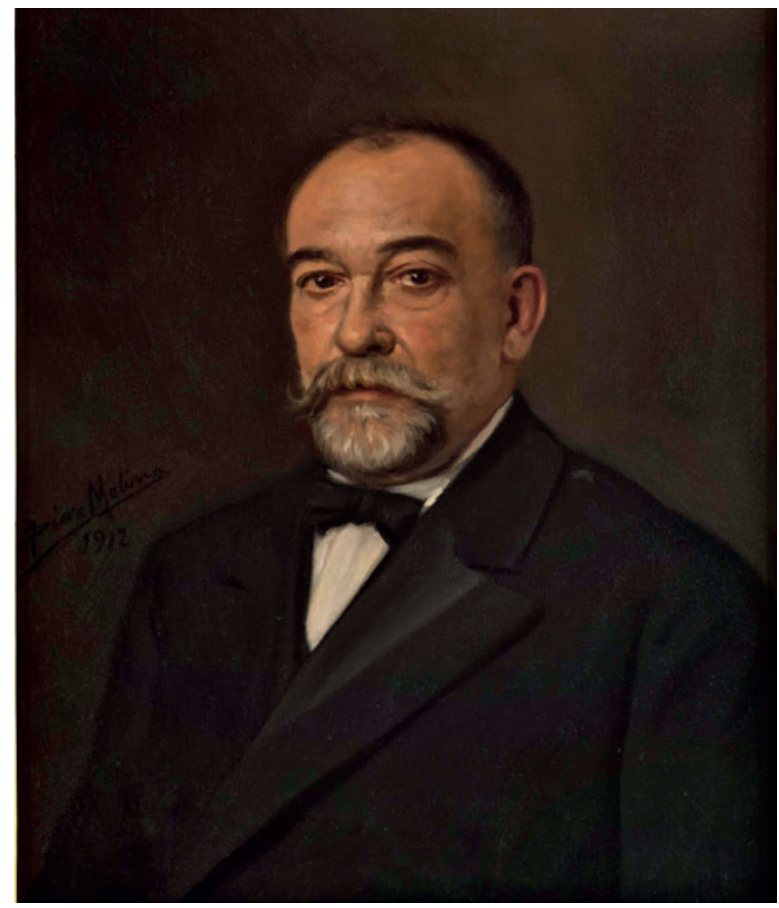

Figura 3. Rodrigo Amador de los Ríos, Director del Museo Arqueológico Nacional, 1912. MAN.

Por otra parte, como puede observarse (tabla 1), no pudo haber una rivalidad de Amador de los Ríos con Mélida para poder acceder a la dirección del Museo Arqueológico Nacional, pues era 7 años mayor, tenía casi 8 años de mayor antigüedad en el cuerpo, y la responsabilidad de Jefe de Sección la empezó a ejercer provisionalmente en Edades Media y Moderna desde el 1 de julio de 1881 (AMAN EP RAR 39), mientras que Mélida pasó a ser Jefe de Sección de Protohistoria y Edad Antigua a partir de 1884, donde había comenzado en 1876 como aspirante y sin sueldo (Castañeda 1934: 6), al ascender Rada a Jefe de Primer Grado, quien había sido el encargado de la Sección Primera desde el 15 de agosto de 1881 (AMAN EP JDRD 13). Además, para Mélida en 1911 su prioridad era sustituir a Catalina García como catedrático de Arqueología en la Universidad Central de Madrid. Como le señalaba a su compañero de las excavaciones en Mérida, Maximiliano Macías, "una grandísima satisfacción personal tengo que comunicar a Vd., mi buen amigo (...) he sido propuesto por unanimidad por la Academia de la Historia, en la Sección de Ciencias Históricas de la Facultad de Letras y en el Consejo de Instrucción Pública, para catedrático de Arqueología de la Universidad. ¡El sueño de mi vida!” (Mélida 16-7-1911, Caballero y Álvarez 2011: 64-65 n 71). 
Un trabajo de Amador de los Ríos sobre la historia y el presente del Museo Arqueológico Nacional, redactado durante la etapa de Catalina García, es muy crítico con la situación existente en 1903 (Amador de los Ríos 1903b), siendo impensable que lo hubiese escrito de ser entonces el director del museo, pero permite valorar bien su opinión sobre la trayectoria del museo desde su fundación en 1867, al que se incorporó al año siguiente.

Uno de sus objetivos fue reivindicar la figura de su padre como director por estimular las donaciones de piezas al museo en 1868, a pesar de llegar a ser "amenazado de muerte en los primeros días de la revolución por sus propios dependientes, á quienes molestaba el trabajo que, cumpliendo con su obligación, les imponía”. También destaca la etapa de Ventura Ruiz Aguilera (1868-72), que considera "la época más venturosa para el museo", favorecida por las incautaciones propiciadas durante el Sexenio Revolucionario y el envío de Comisiones a la distintas provincias para captar piezas para el entonces nuevo Museo Arqueológico Nacional (Amador de los Ríos 1903b: 49-50), con quien tuvo una excelente relación, calificándolo de "mi cariñoso amigo" (Amador de los Ríos 1911c: 93), a pesar de que fueron los años en que había sido declarado cesante.

Igualmente valora positivamente el periodo de Antonio García Gutiérrez (1872-84), pues “sólo elogios merece la conducta seguida por el Sr. García Gutiérrez en los doce largos años que desempeñó el cargo honroso de Director", periodo en que pudo reincorporarse desde 1875 .

En cambio, es mucho más dura su valoración con sus sucesores en los últimos años, pues "Poco ó nada interesante $(. .$.$) ofrecen los períodos en que sucesiva-$ mente ejercieron la dirección los Sres. D. Francisco Bermúdez Sotomayor, D. Basilio Sebastián Castellanos de Losada, D. José Villaamil y Castro y D. Carlos Castrobeza" y Fernández (Amador de los Ríos 1903b: 51), que también fue responsable de la Sección Cuarta del museo, Numismática y Glíptica.

En cambio, es muy interesante su buena valoración de Rada, a la hora de analizar sus posibilidades de acceder a la dirección del Museo Arqueológico Nacional en 1900, estando entonces reciente la muerte de Rada en 1901. Amador de los Ríos (1903b: 52) lo califica de "polígrafo infatigable y hombre dotado de clara inteligencia y de amor acrisolado hacia la Arqueología, el inolvidable don Juan de Dios de la Rada y Delgado (...) que, juntamente con D. Paulino Savirón (...) hizo el acomodo, reparto é instalación de las colecciones del Museo, en aquella parte que no quedó hecha antes de Noviembre de 1868", al ser cesado como director José Amador de los Ríos.
En su etapa se redujo el presupuesto de adquisiciones del museo "á su mitad (...) y al Museo no eran ofrecidos en venta sino aquellos objetos de que no habían los anticuarios podido deshacerse en el extranjero, ó que no habían querido admitir los coleccionistas nacionales" (Amador de los Ríos 1903b: 59).

Finalmente, "Juan Catalina García, Jefe actual (...) Lleno venía de nobilísimos propósitos; pero nada tampoco ha conseguido de la Superioridad (...) pues todos sus esfuerzos se han estrellado (...) en la tradicional apatía de nuestros gobernantes, á quienes con repetida insistencia ha expuesto la miserable situación á que ha sido llegado el Museo" (Amador de los Ríos 1903b: 69). "La consignación actual es de tres mil pesetas anuales para la adquisición de objetos, y mil para gastos de material, en los que entran los de escritorio, calefacción, limpieza, construcción de aparatos, etc. (...) consignación, que con ella no tiene ni para adquirir objetos, ni para hacer obra de ninguna especie" (Amador de los Ríos 1903b: 68 n. 1).

No dejó pasar la ocasión para criticar a Riaño, con el que quedó enfrentado después de la aprobación del Catálogo Monumental en 1900, recordando que trabajaba a cuenta de museos extranjeros, pues "en Toledo, dejaron que por el Sr. Riaño les fuera arrebatada alguna reliquia interesante, como la famosa botica de aquella ciudad, hoy existente en uno de los Museos de Inglaterra" (Amador de los Ríos 1903b: 50).

En la etapa bajo su dirección, una de las prioridades de Amador de los Ríos fue la adquisición de nuevas piezas, que pasaron entre enero de 1911 y el 4 de marzo de 1916 a sumar 2.786 piezas nuevas, 2.143 por adquisiciones, incluyendo la colección Vives, y 643 por donaciones (Mélida 1917: 8). Respecto a la exhibición, "han sido preparados dos salones nuevos para las antigüedades de las civilizaciones orientales, tres para la instalación del valiosísimo donativo del Excmo. Sr. Marqués de Cerralbo y para el que le tenían prometido los eminentes arqueólogos hermanos Siret" (Anónimo 1916: 346).

Ya en 1913, Amador de los Ríos presentó presupuesto para instalar la colección Cerralbo en el Museo Arqueológico Nacional, que fue aceptada como donativo al Estado por Real Orden de 29 de febrero de 1915. Amador de los Ríos pidió medios para el traslado e instalación al Ministerio de Instrucción Pública el 6 de marzo, que volvió a recordar en otro escrito de 7 de mayo. Por otra parte, hubo discrepancias sobre la instalación y vitrinas, que propuso Amador de los Ríos inicialmente de tipo provisional el 6 de marzo, lo que su heredero rechazó el 11 de marzo, solicitando la 
Tabla 1. Carreras administrativas de Catalina García (AGA 31/6520/54; Mederos, e.p.), Rodrigo Amador de los Ríos (AGA 31/06499 y AMAN EP RAR), y José Ramón Mélida (AMAN EP JRMA; Díaz-Andreu 2004: xxix-xxx).

\begin{tabular}{|c|c|c|c|}
\hline Puesto Escalafón & Catalina García & Rodrigo Amador de los Ríos & José Ramón Mélida \\
\hline Aspirante sin sueldo & & & $4-2-1876$ \\
\hline Ayudante de $3^{\circ}$ Grado & & $25-6-1868$ & $23-4-1881$ \\
\hline Ayudante de $2^{\circ}$ Grado & & $19-3-1875$ & $13-10-1884$ \\
\hline Oficial de $3^{\circ}$ Grado & & $18-7-1884$ & $26-9-1888$ \\
\hline Oficial de $2^{\circ}$ Grado & $12-5-1885$ & $16-2-1889$ & $30-7-1892$ \\
\hline Oficial de $1^{\circ}$ Grado & $29-8-1890$ & $9-12-1892$ & $1-7-1895$ \\
\hline Jefe de $3^{\circ}$ Grado & $9-12-1892$ & $1-7-1895$ & $3-7-1900$ \\
\hline Jefe de $2^{\circ}$ Grado & $23-10-1896$ & $11-6-1901$ & $12-2-1910$ \\
\hline $\begin{array}{c}\text { Jefe de } 1^{\circ} \text { Grado- Jefe de } \\
\text { Administración Civil de } 4^{\text {a }} \text { Clase }\end{array}$ & $4-8-1900$ & $30-5-1905$ & 1905 \\
\hline $\begin{array}{c}\text { Inspector de } 3^{\circ} \text { Grado-Jefe de } \\
\text { Administración Civil de } 3^{\text {a }} \text { Clase }\end{array}$ & $19-5-1905$ & $14-1-1911$ & $1-1-1915$ \\
\hline $\begin{array}{c}\text { Inspector de } 2^{\circ} \text { Grado-Jefe de } \\
\text { Administración Civil de } 2^{\text {a }} \text { Clase }\end{array}$ & $23-4-1909$ & $12-2-1911$ & \\
\hline $\begin{array}{c}\text { Inspector de } 1^{\circ} \text { Grado-Jefe de } \\
\text { Administración Civil de } 1^{\text {a }} \text { Clase }\end{array}$ & & $8-1-1915$ & \\
\hline
\end{tabular}

instalación en una sala permanente dedicada a sus excavaciones (AMAN 1913/13 y 1915/15; Barril y Cerdeño 1997: 526-527).

\section{LA REDACCIÓN DE LOS CATÁLOGOS MONUMENTALES DE MÁLAGA, HUELVA, ALBACETE Y BARCELONA}

Los Catálogos Monumentales que redactó Amador de los Ríos fueron varios años después de su inicio en 1900 , a partir de su nombramiento por la Real Orden de 22 de enero de 1907, bajo presidencia de Antonio Aguilar y Correa, marqués de la Vega de Armijo, siendo Ministro de Instrucción Pública Amalio Gimeno y Cabañas, y como figura clave el conde de Romanones como Ministro de Gobernación. Primero fue Málaga, una provincia importante en el último cuarto de siglo XIX por ser la de nacimiento de Cánovas del Castillo hasta su asesinato en 1897 y, a su muerte, de la mujer del líder de los conservadores, Francisco Silvela, casado con Amalia Loring Heredia, residiendo además allí su hermano, el arquitecto Ramiro Amador de los Ríos.
Se le concedió 12 meses para su redacción con 800 pesetas mensuales, es decir, 9.600 pesetas. Los primeros dos volúmenes fueron entregados el 10 de enero de 1908, solicitando una prórroga de 4 meses por haber sufrido enfermedad y una inundación en la provincia, que la Comisión Mixta propuso ampliar a 8 meses, ya sin remunerar, que se aprobó el 8 de junio, entregando el 24 de septiembre los volúmenes 3 y 4, que recibieron informe muy favorable de la Comisión Mixta el 7 de octubre, con orden de pago de la segunda parte de su cuantía el 28 de noviembre (Amador de los Ríos 1908; López-Yarto 2010; AGA 31/1848).

Durante su realización, visitó en 1908 el entorno del faro de Torrox, en el extremo oriental de la provincia de Málaga, donde se observaban mosaicos y tégulas romanos en la margen derecha de la desembocadura del río Torrox, yacimiento que después comenzó a excavar el farero, Tomás García y Ruiz ${ }^{3}$ (Amador de los Ríos 1914b: 237, 240-241). El texto está plagado de

3. Autorizadas por la Junta Superior de Excavaciones y Antigüedades en dos anualidades, creó un pequeño museo, cuyo contenido fue adquirido finalmente por el Estado que depositó los materiales en el Instituto General y Técnico de Málaga 
referencias arqueológicas sobre tiempos prehistóricos (Neolítico y de los Metales) e históricos (Fenicio, Edad Antigua y Edad Media -visigodo, mahometano y reconquista-) (Amador de los Ríos 1908).

El segundo fue Huelva, por Real Orden de 23 de noviembre de 1908, ya con los conservadores, bajo presidencia de Antonio Maura Montaner y siendo Ministro de Instrucción Pública, Faustino Rodríguez Sampedro, provincia vinculada a su familia por ser parte del "territorio del antiguo Reino de Sevilla" (Amador de los Ríos 1908: 12) y haber redactado previamente el volumen en la colección España. Sus monumentos y artes. Su naturaleza é historia (Amador de los Ríos 1891a), momento en que realizó el estudio en Palos de la iglesia mudéjar de San Jorge y su Puerta de los Novicios (Amador de los Ríos 1903c). Para Huelva nuevamente se le concedieron 12 meses para su redacción y 800 pesetas mensuales, recibiendo amplio apoyo del Gobernador Civil que solicitó a los alcaldes toda la ayuda posible, entregado en 2 volúmenes de texto y un tercero de láminas en 1909. Fue informado muy favorablemente por la Comisión Mixta el 17 de enero de 1910, que presidía el Conde de Cedillo, recibiendo la orden de pago el 26 de enero (Amador de los Ríos 1909; López-Yarto 2010; AGA 31/1848).

En el tercer catálogo, la provincia de Albacete, por Real Orden de 31 de marzo de 1911, bajo presidencia de José Canalejas y Méndez, siendo Ministro de Instrucción Pública Amós Salvador Rodrigáñez, influía la procedencia murciana de su mujer pues Albacete incluye "antiguas demarcaciones de Cuenca, Murcia y La Mancha Alta" (Amador de los Ríos 1911: 7), y haber también redactado previamente el volumen específico de Murcia y Albacete (Amador de los Ríos 1889) en la colección España. Sus monumentos y artes. Su naturaleza é historia. Se repitieron las condiciones, 12 meses y 800 pesetas mensuales, aunque se adelantaron los pagos recibiendo la segunda parte ya el 19 de febrero de 1912. Sin embargo, no consiguió finalizarlo a tiempo, solicitando prórroga el 4 de marzo, que fue concedida el día 15 por la Comisión Mixta, la cual recibió 2 volúmenes de texto y 2 de ilustraciones el 5 de noviembre, nuevamente informados muy favorablemente por la Comisión Mixta, recibiendo la aceptación final del Rey el 19 de noviembre (Amador de los Ríos 1909; López-Yarto 2010; AGA 31/1848). Coincidiendo con su elaboración, realizó un viaje como Inspector General de Museos, para el que solicitó permiso el 27 de junio de 1912, que incluía los museos de Albacete, Murcia, Alicante y Valencia (AGA 31/06499).
El último encargo, ya siendo director del Museo Arqueológico Nacional, fue Barcelona, por Real Orden de 30 de abril de 1913, bajo presidencia del conde de Romanones y siendo Ministro de Instrucción Pública Antonio López Muñoz. Esta provincia le interesaba especialmente para su análisis de arte islámico en Cataluña la Vieja, primero Gerona (Amador de los Ríos 1915a) y en particular Barcelona y Tarragona, titulado Reliquias de los musulmanes en Cataluña (Amador de los Ríos 1915b: 193 n. 1), pues consideraba habían quedado minimizadas en la reivindicación del románico catalán por Puig y Cadafalch, Falguera y Goday (1911) con L'Arquitectura romanica a Catalunya, donde señalaban que la influencia de los musulmanes en Cataluña era "en nosaltres quasi nula".

Propuesta su elaboración por la Comisión Mixta el 17 de febrero de 1913, con similar tiempo de redacción y cuantía, solicitó dos prórrogas de 4 meses el 1 de enero y el 18 de mayo de 1914, entregando 2 volúmenes de texto y 2 de ilustraciones el 30 de julio de 1914, siendo Narciso Sentenach quien informó positivamente el trabajo. Amador de los Ríos solicitó una gratificación por los gastos en demasía que le había supuesto la elaboración del catálogo, que fue aceptada y se le concedieron 1.250 pesetas adicionales (Amador de los Ríos 1914a; López-Yarto 2010; AGA 31/1848).

Como autor del volumen sobre Santander (Amador de los Ríos 1891b) en la colección España. Sus monumentos y artes. Su naturaleza é historia, se le encargó también la provincia de Santander para el $\mathrm{Ca}$ tálogo Monumental de España, siendo propuesto el 26 de enero de 1915 por la Comisión Mixta, trabajo que figura como redactado en 1917 (López-Yarto, 2010), aunque parece que su fallecimiento hizo que fuese encargado, o quizás mejor finalizado, por el periodista de El Heraldo de Madrid, Cristóbal de Castro, quien se definía a sí mismo como "publicista, poeta, dramaturgo, vicepresidente de la sección de literatura del Ateneo de Madrid" y "Presidente de la Previsión Periodística” (López-Yarto 2010).

\section{LAS CAMPAÑAS ARQUEOLÓGICAS EN ITÁLICA}

En 1912 se le encargó por la Junta Superior de Excavaciones la reanudación de las excavaciones en Itálica (Santiponce, Sevilla) a Rodrigo Amador de los Ríos, continuando la tradición familiar que ya habían tenido primero su padre, José Amador de los Ríos, seguidas por las de su tío, Demetrio de los Ríos, cuyas 
excavaciones había visitado en 1874, con 25 años, “y admiré los hermosos mosaicos por él descubiertos en Las Coladas" (Amador de los Ríos 1911b: 22).

No obstante, ya por Real Orden del 4 de febrero de 1911, el Ministro de Instrucción Pública y Bellas Artes y compañero de Amador de los Ríos en la Real Academia de Bellas Artes de San Fernando, el liberal Amos Salvador Rodrigáñez, le encargó la dirección de las excavaciones en Itálica (Amador de los Ríos 1911d: 122), desplazándose al mes siguiente de marzo a visitar las ruinas de Itálica en "oficial misión" dentro de la declaración como Monumento Nacional y asumir la dirección (Amador de los Ríos 1911a: 73, 1911d: 122 y 1911e). Allí visitó con el alcalde el lugar donde en 1900 había aparecido la estatua de Diana en un corral de la calle de Siete Revueltas, adquiriendo para el Museo Arqueológico Nacional un capital corintio (Amador de los Ríos 1911a: 82-83). También estuvo en la zona de las Eras del Monasterio donde Ivo de la Cortina había excavado en 1839, en la cual "levántase hoy una barriada de labradores, dividida en calles, denominadas pomposamente dos de ellas de Trajano y del Duque de Medinasidonia", dentro del barrio de la Alegría (Amador de los Ríos 1911a: 86 y 1916a: 396). El 14 de diciembre de 1911 presentó el informe al ministro para la declaración de las ruinas de Itálica como Monumento Nacional (Amador de los Ríos 1911e).

También años antes había realizado una visita a Madinat al-Zahra', recuperando algunas piezas para el Museo Arqueológico Nacional, indicando la necesidad de comprar los terrenos y "emprender excavaciones" (Amador de los Ríos 1906: 45 y 48).

Como refleja en un artículo antes de empezar las excavaciones, su formación le llevaba a preocuparse por fases poco investigadas hasta entonces en Itálica, señalando que la presencia de epígrafes sepulcrales en el Museo Arqueológico Provincial de Sevilla y de capiteles visigodos indicaban que la ciudad seguía siendo habitada en el siglo VI d.C. Además, apoyándose en las fuentes árabes, sugería que la ocupación había continuado hasta fines del siglo VIII a.C. cuando poblaron Sevilla, "dejando arruinada a Medina Thálica" (Amador de los Ríos 1911b: 13, 15-16). Precisamente, como consideraba que "de haber subsistido Itálica y de haber habitado en ella la gente visigoda", pensaba "cuando sea posible desarrollar el plan de excavaciones, que quiméricamente pretendo" (Amador de los Ríos 1912b: 288-289), para poder definir esos periodos.

En segundo lugar, advertía que "hay que convencerse de que Itálica, ni fue nunca de nuestras ciudad romanas la mayor y la más importante, aunque haya sido la más cantada, la más renombrada y estudiada con más empeño, ni obtuvo jamás la importancia política ó militar que obtuvieron otras varias poblaciones de una y otra Hispania", por lo que "Soñar con (...) una nueva Pompeya, es quimera vana". No obstante, indicaba que "Itálica merece (...) las excavaciones proyectadas, siempre que el Estado facilite los recursos" (Amador de los Ríos 1911c: 109-110). Aún así, la aprobación de la Ley y Reglamento de Excavaciones del 8 de julio fue acogida con escepticismo por Amador de los Ríos (1911c: $110 \mathrm{n}$. 1) quien señalaba que "me temo que á pesar de los excelente propósitos (...) no haya en la práctica de producir los efectos que con ella se pretenden".

Las excavaciones las inició en marzo de 1912, aunque por error señala 1911 (Amador de los Ríos 1912b: 280). En teoría se trató de 3 campañas, en 1912, 1913 y 1915 según Díaz-Andreu (2003: 58 tabla 1), pero no especifica la cantidad de subvención anual recibida. Utilizó en el campo a un capataz que coordinaba a los obreros, iniciando la campaña en "la galería anular del segundo cuerpo en el sector septentrional, partiendo del primer vomitorio" (Amador de los Ríos 1916a: 408). A su juicio, la dotación económica era insuficiente para acometer obras e impedir que las aguas torrenciales anegasen anualmente en el anfiteatro y permanecieran largo tiempo estancadas en las construcciones subterráneas, pues "siendo exigua la consignación para las excavaciones concedida, vime (...) con gran sentimiento, precisado a desistir de mis propósitos" (Amador de los Ríos 1916a: 405).

Precisamente, para conseguir superar este problema, "logré en 1914 abriese desde el referido extremo [en el sector del Mediodía] la Comisión Provincial de Monumentos de Sevilla" (Amador de los Ríos 1916a: 10), dirigida por su vicepresidente, José Gestoso y Pérez, que desescombró el pasillo abovedado subterráneo en dirección a la entrada oriental entre octubre de 1914 y finales de enero de 1915 (Beltrán Fortes 2002: 368), o "“corredor' de la parte de Levante", sin embargo, "no ha servido para nada" (Amador de los Ríos 1916a: 10 y 16). El segundo objetivo del trabajo de Gestoso fue vaciar la zona central de la arena, que "la propia Comisión Provincial de Monumentos ha hecho en su totalidad practicable, al limpiar en el otoño de 1914 el cuadro general de la arena" (Amador de los Ríos 1916a: 16).

En esta campaña de Gestoso destaca particularmente la localización de una estatua egipcia en roca, sobre la cual Mélida le informó que se trataba de un original egipcio entre las dinastías XVIII-XXII de Ra, Amón o Horus, que Beltrán Fortes (2002: 370) apunta pudo proceder de un santuario dentro del anfiteatro vinculado 
a una divinidad egipcia, como existía uno vinculado a Dea Caelestis. La estatua egipcia ha sido fechada hacia el 750-500 a.C. por Gamer-Wallert (1998: 9), atribuyéndola a Ptah, Amón o Anubis y suponiendo que llegó a la península ibérica en época romana.

Antes de iniciar sus excavaciones, Amador de los Ríos (1911b: 7 y 1911c: 95-96) suele referirse muy educadamente sobre la labor de Gestoso, al que denomina "mi excelente amigo Gestoso", "mi docto y querido amigo Sr. Gestoso" o el "excelente criterio el arqueólogo hispalense Sr. Gestoso”. Un año después su opinión no había cambiado cuando lo califica de "mi antiguo y docto amigo el infatigable arqueólogo sevillano D. José Gestoso" (Amador de los Ríos 1912b: 288).

Se ha sugerido por Rodríguez Oliva y Beltrán Fortes (2008: 50) que los enfrentamientos de Amador de los Ríos con los miembros de la Comisión Provincial de Monumentos de Sevilla, y en particular con José Gestoso Pérez, provocaron su regreso a Madrid, aunque es más lógico que simplemente dejara las excavaciones al producirse su jubilación en marzo de 1916, abandonando la dirección del Museo Arqueológico Nacional. Había poco dinero ese año, como señala Mélida, "Ya despachó la Junta el informe o propuesta para el crédito de las excavaciones, señalando las 15.000 pesetas de costumbre para Numancia y Mérida (esto es las mías) y unas pocas pesetas para Cádiz. Lo de Itálica queda en suspenso y lo mismo lo demás" (Mélida 27-21916, Caballero y Álvarez 2011: 115 n $^{\circ} 145$ ).

En todo caso, las divergencias existían como ha señalado Beltrán Fortes (2002: 367 n. 6), y el principal conflicto estalló en 1915 con la construcción de un edificio de museo que se levantó en el ámbito del anfiteatro, a propuesta de la Comisión Provincial de Monumentos de Sevilla, pero que Amador de los Ríos no apoyaba.

A la hora de enumerar los problemas que se encontró Amador de los Ríos señalaba como las dos primeras, "la escasa consignación [de dinero] que señalada tienen, y de la enemiga con que es por ciertos intelectuales hispalenses mirada la persona no nacida en Sevilla que las tenga a su cargo, cual en 1840 hubo de acontecer respecto de don Ibo de la Cortina (...) Algo de esto ha ocurrido también conmigo, por no ser sevillano" (Amador de los Ríos 1916a: 20 n. 2). El tercer problema era la propiedad del terreno, por el "desconocimiento absoluto que, oficial y particularmente, existe respecto de los linderos" siendo "necesario que el Estado adquiera los terrenos circundantes" porque "Oprimido el Anfiteatro por las tierras de labor que le circuyen en su mayor parte, no hay sitio, por ningún lado, del cual pueda hacerse vaciadero de las tierras y de los escombros extraídos, los cuales son vertidos en los predios colindantes, cuando los propietarios lo consienten, o en la Vegueta; y sin contar con lo costosa que resulta esta labor a causa de no poder en ella ser sino caballerías empleadas" (Amador de los Ríos 1916a: 2122). Finalmente, no poder "impedir que las aguas pluviales procedentes del predio con el cual linda aquél por el Ocaso se precipiten con increíble violencia por el indicado extremo, convirtiendo la fossa en pestilente estanque, enfangando las galerías (...) y derrumbando grandes trozos de terreno que ciegan e inutilizan los trabajos hechos en el eje occidental" (Amador de los Ríos 1916a: 22).

\section{LA TRASMISIÓN DE LA DIRECCIÓN DEL MUSEO ARQUEOLÓGICO NACIONAL A MÉLIDA}

La jubilación de Amador de los Ríos el 3 de marzo de 1916 con categoría de Inspector Primero y Jefe de Administración Civil de Primera Clase, sirvió para concederle también el grado de Jefe Superior de Administración Civil, produciéndose su cese como director del Museo Arqueológico Nacional el 4 de marzo (AGA 31/06499), al cumplir 67 años, después de haber sido prorrogado en el cargo durante 2 años por Real Decreto de 23 de octubre de 1913, cuando tenía 64 años (AGA 31/06499). Su marcha fue acogida con indiferencia ese día 3 de marzo, "Amador de los Ríos (...) viene a despedirse y nadie le hace caso, bajamos [Francisco Álvarez-]Ossorio y yo [Ignacio Calvo] con él hasta la puerta de la calle" (MAN GN Calvo diario p. 99).

La elección de Mélida no parece haber presentado problemas. Le facilitó las cosas que llegara al gobierno un amigo suyo, el conde de Romanones, Álvaro de Figueroa y Torres, como Presidente del Consejo de Ministros desde el 9 de diciembre de 1912, quien colocó a Julio Burell Cuéllar como Ministro de Instrucción Pública y Bellas Artes.

"Puede Vd. figurarse la satisfacción con que voy al Museo Arqueológico (...) La Junta de nuestro cuerpo me ha propuesto para el cargo por aclamación (lo que no esperaba); y las gentes ajenas a la carrera votan también a mi favor; de modo que es grande mi contento". La sucesión fue muy rápida, "el día 3 cumple Amador el tiempo para su jubilación y (...) tomaré posesión el 4; y si no el 10" (Mélida 27-2-1916, Caballero y Álvarez 2011: 114-115 n 145). La Junta Facultativa de Archivos, Bibliotecas y Museos se reunió el 15 de febrero y 
Tabla 2. Únicas excavaciones subvencionadas en España por la Junta Superior de Excavaciones Arqueológicas entre 1912-15.

\begin{tabular}{|c|c|c|c|c|}
\hline $\begin{array}{c}\text { Directores de } \\
\text { excavaciones } \\
\text { subvencionadas }\end{array}$ & 1912 & 1913 & 1914 & 1915 \\
\hline Mélida & $\begin{array}{l}\text { Numancia (Soria) } \\
\text { Teatro de Mérida } \\
\text { (Badajoz) }\end{array}$ & $\begin{array}{l}\text { Numancia (Soria) } \\
\text { Teatro de Mérida } \\
\text { (Badajoz) }\end{array}$ & $\begin{array}{c}\text { Numancia (Soria) } \\
\text { Teatro de Mérida } \\
\text { (Badajoz) }\end{array}$ & $\begin{array}{l}\text { Numancia (Soria) } \\
\text { Teatro y Anfiteatro de } \\
\text { Mérida (Badajoz) }\end{array}$ \\
\hline Amador de los Ríos & $\begin{array}{l}\text { Anfiteatro de Itálica } \\
\text { (Sevilla) }\end{array}$ & $\begin{array}{l}\text { Anfiteatro de Itálica } \\
\text { (Sevilla) }\end{array}$ & & $\begin{array}{l}\text { Anfiteatro de Itálica } \\
\text { (Sevilla) }\end{array}$ \\
\hline Velázquez & $\begin{array}{l}\text { Medina Az-Zahara } \\
\text { (Córdoba) }\end{array}$ & $\begin{array}{l}\text { Medina Az-Zahara } \\
\text { (Córdoba) }\end{array}$ & & $\begin{array}{l}\text { Medina Az-Zahara } \\
\text { (Córdoba) }\end{array}$ \\
\hline Sentenach & Termes (Soria) & Clunia (Burgos) & Clunia (Burgos) & \\
\hline Calvo & & Termes (Soria) & $\begin{array}{c}\text { Cuevas de la Zorrera } \\
\text { (Jaén) }\end{array}$ & $\begin{array}{c}\text { Clunia (Burgos) } \\
\text { Cuevas de la Zorrera (Jaén) }\end{array}$ \\
\hline Quintero & & & & $\begin{array}{l}\text { Punta de la Vaca (Cádiz) } \\
\text { Puerta de Tierra (Cádiz) }\end{array}$ \\
\hline Blázquez & & & & $\begin{array}{c}\text { Vías romanas del Valle del } \\
\text { Duero }\end{array}$ \\
\hline
\end{tabular}

lo propuso por unanimidad (Díaz-Andreu 2004: 1xxiv n. 143). El 4 de marzo, Mélida cesó como director del Museo de Reproducciones Artísticas (AMAN EP JRMA 35c; Casado 2006: 313) y el día 9 tomó posesión (AMAN EP JRMA 36; Díaz-Andreu 2004: lxxiv).

Su pase al Museo Arqueológico Nacional además permitía compensar a Amador de los Ríos, quien al igual que sucedió previamente con Rada y Delgado, al dejar el Museo Arqueológico por jubilación y ser Académico de Bellas Artes, acabó dirigiendo el Museo de Reproducciones Artísticas, como proyección de la Galería de Escultura y Taller de Vaciados en la Real Academia de Bellas Artes de San Fernando, nombramiento que recibió 5 días después, por Real Orden de 9 de marzo de 1916, de carácter "gratuito" (AGA 31/06499; Casado, 2006: 349 n. 1879), el mismo día que tomó posesión Mélida. Sin embargo, Amador de los Ríos apenas detentó el nuevo cargo pues ya el 14 de abril de 1917, por encontrarse enfermo, solicitó la renuncia al cargo de director pues "necesita de temporal reposo y atender a su salud", aceptada el 19 de abril y publicada como Real Orden el 27 de abril (AGA 31/06499), falleciendo pocos días después, el 3 de mayo de 1917. En la dirección del Museo de Reproducciones Artísticas fue sustituido por una persona de confianza de Mélida, Narciso Sentenach, cuyo ingreso en la Real Academia de Bellas Artes de San Fernando había contestado Mélida (1907).
$\mathrm{Su}$ fallecimiento, con el relativamente próximo de su cuñado, Francisco Fernández y González, el 30 de junio de 1917, supuso el final de la influyente familia de los Amador de los Ríos en la arqueología española a lo largo de casi un siglo.

Finalmente, cabe señalar que a pesar de la muerte de Amador de los Ríos poco después de abandonar la dirección del Museo Arqueológico Nacional y ser ambos compañeros en la Real Academia de Bellas Artes de San Fernando, Mélida (1917: 8) no se molestó en escribir una necrológica de Amador de los Ríos, su inmediato predecesor en el cargo, aunque sí señaló puntualmente "la labor inteligente y asidua que por espacio de más de cuarenta años realizó en este museo".

\section{CONCLUSIONES}

Rodrigo Amador de los Ríos nació en una de las familias más importantes del panorama cultural español de mediados del siglo XIX, hijo del académico y director del Museo Arqueológico Nacional, José Amador de los Ríos, sobrino del académico y arquitecto, Demetrio de los Ríos y del correspondiente granadino, Diego Amador de los Ríos, y cuñado del académico y Rector de la Universidad Central, Francisco Fernández y González. 
Con un buen expediente académico, aunque estudió el bachillerato en Sevilla y empezó en su universidad, se licenció en Filosofía y Letras en Granada el 5 de junio de 1868 y también en Granada terminó el Grado de Bachiller en Derecho el 17 de junio de 1868, obteniendo el título de Licenciado en Derecho Civil y Canónico el 14 de junio de 1869 en la Universidad Central de Madrid.

Una vez licenciado, podía presentarse a Ayudante de Tercer Grado del Cuerpo de Archiveros, Bibliotecarios y Anticuarios, con destino en el Museo Arqueológico Nacional, que dirigía su padre, y su solicitud fue aceptada inmediatamente por el Ministro de Fomento, el 25 de junio de 1868, con 19 años. Sin embargo, la revolución de septiembre de 1868 condujo al cese de su padre como director y también de Rodrigo Amador, apenas 5 meses después de haber ingresado, el 20 de noviembre de 1868.

El cese le llevó probablemente a cumplir el servicio militar poco antes del estallido de la Tercera Guerra Carlista en 1872 y a trabajar en el bufete del ex-ministro de Gracia y Justicia, José María Fernández de la Hoz. Con la mayor estabilidad política después del golpe de estado del capitán general Pavía el 2 de enero de 1874, y el gobierno de concentración bajo presidencia del general Serrano, finalizó su doctorado en Filosofía y Letras el 25 de junio de 1874 y estuvo durante 9 meses como Auxiliar de la cátedra de Principios Generales de Literatura y Literatura Española en la Universidad Central.

Un nuevo golpe de estado del general Martínez Campos, el 29 de diciembre de 1874, a favor de Alfonso XII, inauguró la Restauración monárquica y Cánovas del Castillo asumió la presidencia del gobierno en enero de 1875 , lo que permitió su reingreso en el Cuerpo de Archiveros con un ascenso a Ayudante de Segundo Grado, reconociéndole en parte la antigüedad durante su cese, incorporándose por su especialidad en la Sección Segunda de Edades Media y Moderna, con destino en las salas de arte hispano-mahometano y estilo mudéjar, desde el 19 de marzo de 1875.

Amador de los Ríos, que había sido alumno en Granada entre 1866-68 del catedrático de Árabe, Francisco Javier Simonet, solicitó una comisión especial para el estudio de las inscripciones árabes de España y Portugal, que le fue concedida en julio de 1875 y en junio de 1877, que culminaron con la Memoria acerca de algunas inscripciones arábigas de España y Portugal (1883), que lo convierte en el mejor especialista español en inscripciones arábigas de la segunda mitad del siglo XIX, realizando un trabajo paralelo al que realizó
Hübner (1869) con las inscripciones latinas. Estos años son también los de mayor productividad científica, con numerosos artículos en el Museo Español de Antigüedades entre 1875-80.

La segunda mitad de los años ochenta consolidó su estabilidad laboral al complementar su trabajo en el museo con otro de Profesor Auxiliar por oposición de la Facultad de Filosofía y Letras, en la cátedra de Historia Crítica de España, desde el 20 de noviembre de 1884. También aprovechó que por tener el título de doctor y ser ayudante de museos podía presentarse como alumno libre a la Escuela Superior de Diplomática, donde se le debió facilitar obtener el título de Archivero pues obtuvo 7 notables en las asignaturas, aprobando el examen de grado el 2 de octubre de 1884 .

Quizás para conseguir su ingreso en la Real Academia de Bellas Artes de San Fernando concentró sus esfuerzos en la publicación de 4 monografías dentro de la colección España. Sus monumentos y artes. Su naturaleza é historia, Burgos (1888), Murcia y Albacete (1889), Huelva (1891) y Santander (1891), siendo elegido en enero de 1890. En cambio, su falta de sintonía con el catedrático de árabe Francisco Codera le impidió acceder a la Real Academia de la Historia, quien promocionó a Vives en 1899.

La última década del siglo XIX se encontró en su trayectoria con el ascenso de Catalina García y López que había sido nombrado Catedrático de Arqueología y Ordenación de Museos desde 1885 y contaba con el apoyo del ala derecha del Partido Liberal-Conservador, encabezada por los hermanos Alejandro y Luis Pidal, y de los tradicionalistas carlistas del Marqués de Cerralbo. Tenía 4 años más de edad, pero ambos se licenciaron casi simultáneamente, Amador de los Ríos en Granada en junio de 1868 y Catalina García en Madrid en mayo de 1868, aunque no realizó el examen de grado en junio que otorgaba la licenciatura. Así, en la Exposición Histórica-Europea, cuyo objetivo era mostrar la cultura de España y Portugal entre los siglos XV, XVI y primera mitad del siglo XVII, pese a ser ya Académico desde 1890 y Jefe de la Sección Segunda de Edades Media y Moderna del Museo Arqueológico Nacional, se eligió como subdelegado civil de la exposición a Catalina García, quien se apoyó en Vives y Codera como asesores para relegarlo. También le afectó mucho la premura en el traslado de las colecciones del Museo Arqueológico a su nueva sede del Palacio de Museos y Bibliotecas, cuyo espacio expositivo además quedó notablemente mermado para beneficiar a la Biblioteca Nacional. El caso es que parece que optó unos meses por participar como voluntario en la guerra 
de Melilla o guerra de Margallo de 1893, quizás en calidad de intérprete de árabe, probablemente entre febrero y junio cuando estuvo ausente de Madrid. Su investigación estuvo centrada en la epigrafía árabe, con numerosos artículos sobre nuevos epígrafes entre 1895-1900, sobre todo en el Boletín de la Sociedad Española de Excursiones.

La aprobación del Catálogo Monumental de España en 1900 generó un conflicto dentro de la Real Academia de Bellas Artes de San Fernando, al encabezar Amador de los Ríos y Rada y Delgado el rechazo a la propuesta de su director, Juan Facundo Riaño, de nombrar en exclusiva a Manuel Gómez-Moreno para elaborarlos, que había acordado el Ministro de Fomento, el Marqués de Pidal. La resistencia de ambos, con entrega de un escrito crítico sobre la Real Orden, redactado por Rada poco antes del 25 de junio, irritó al nuevo Ministro de Instrucción Pública y Bellas Artes, García Alix, puesto que ponía en discusión una medida de su predecesor, tomada bajo el mismo Presidente del Consejo, el conservador Francisco Silvela. La coincidencia con el cierre de la Escuela Superior de Diplomática, el 20 de julio, desencadenó la caída de Rada como director del Museo Arqueológico Nacional, que fue jubilado. Para ello, primero fue trasladado Catalina García al Museo Arqueológico Nacional el 29 de julio de 1900, con categoría de Jefe de Primer Grado del Cuerpo y menos de una semana después, el 4 de agosto, ascendido a Inspector de Tercer Grado. Ese mismo día se jubilaba a Rada y Delgado como director y se frustraron las posibles aspiraciones al puesto de Amador de los Ríos, que aún seguía siendo Jefe de Tercer Grado desde 1895 y sólo pasó a Jefe de Segundo Grado el 11 de junio de 1901. En este periodo comenzó a redactar catálogos monumentales, primero Málaga (1908) y después Huelva (1909).

Con el fallecimiento de Catalina García el 14 de enero de 1911, se produjo la rápida sustitución por Amador de los Ríos que ya firma el 19 de enero como director, donde permaneció hasta su jubilación el 3 de marzo de 1916. No pudo haber una rivalidad con Mélida, pues Amador de los Ríos era 7 años mayor y tenía casi 8 años de mayor antigüedad en el cuerpo. En estos años realizó los catálogos monumentales de Albacete (1912) y Barcelona (1914), muy interesado en reivindicar el sustrato islámico en Cataluña. Casi simultáneamente a su ascenso a la dirección, el 4 de febrero de 1911 le fue encargada la dirección de las excavaciones en Itálica, donde una vez propuso el 14 de diciembre la declaración como Monumento Nacional, las inició en marzo de 1912 y continuó hasta 1915.

\section{Agradecimientos}

Este trabajo se adscribe al Grupo de Investigación Hum F-003 de la Universidad Autónoma de Madrid, sobre estudios historiográficos, dirigido por Juan Blánquez. Queremos agradecer la amabilidad de Daniel Gozalbo en el Archivo General de la Administración (AGA), a Aurora Ladero en el Archivo del Museo Arqueológico Nacional (AMAN), a Paula Graneda del Gabinete Numismático del MAN, a Ana Rocasolano y Susana Donoso en el Archivo General de la Universidad Complutense de Madrid (AGUCM) y a los bibliotecarios del Archivo Histórico Nacional (AHN).

\section{BIBLIOGRAFÍA}

Almagro y Cardenas, A. (1904): Biografia del Doctor D. Francisco Javier Simonet, catedrático que fue de lengua árabe en la Universidad de Granada y vicepresidente de la Comisión de Monumentos Históricos y Artísticos de la provincia. Granada, Tipografía-Litografía de Paulino Ventura Travesset.

Amador de los Ríos y Fernández de Villalta, R. (1873): "Lámpara de Abú-Lah Mohamed III de Granada. Lámpara de Orán. En el Museo Arqueológico Nacional". Museo Español de Antigüedades 2: 465-492.

Amador de los Ríos y Fernández de Villalta, R. (1875): Inscripciones árabes de Sevilla. Madrid, Imprenta de Fortanet.

Amador de los Ríos y Fernández de Villalta, R. (1878): Proyecto de Ley de Propiedad Literaria. Madrid, Revista de España 1877-78.

Amador de los Ríos y Fernández de Villalta, R. (1879): Inscripciones árabes de Córdoba. Precedidas de un estudio histórico-crítico de la Mezquita Aljama. Madrid, Imprenta de Fortanet.

Amador de los Ríos y Fernández de Villalta, R. (1883): Memoria acerca de algunas inscripciones arábigas de España y Portugal. Madrid, Imprenta de Fortanet.

Amador de los Ríos y Fernández de Villalta, R. (1884a): "Episodios militares". Revista de España, 96 (384): 587-599.

Amador de los Ríos y Fernández de Villalta, R. (1884b): "Episodios militares". Revista de España, 97 (385): 112-123 y 97 (388): 274-286.

Amador de los Ríos y Fernández de Villalta, R. (1884c): "Episodios militares". Revista de España, 100 (388): 281-293.

Amador de los Ríos y Fernández de Villalta, R. (1888a): España. Sus monumentos y artes. Su naturaleza é 
historia. Burgos. Barcelona, Establecimiento Tipográfico-Editorial de Daniel Cortezo y Cía.

Amador de los Ríos y Fernández de Villalta, R. (1888b): "Estudios arqueológicos. La Sala de Arte hispanomahometano y de Estilo mudéjar, en la Sección Segunda del Museo Arqueológico Nacional”. Revista de España 21 (121): 375-400.

Amador de los Ríos y Fernández de Villalta, R. (1889): España. Sus monumentos y artes. Su naturaleza é historia. Murcia y Albacete. Barcelona, Establecimiento Tipográfico-Editorial de Daniel Cortezo y Cía.

Amador de los Ríos y Fernández de Villalta, R. (1891a): España. Sus monumentos y artes. Su naturaleza é historia. Huelva. Barcelona, Establecimiento Tipográfico-Editorial de Daniel Cortezo y Cía.

Amador de los Ríos y Fernández de Villalta, R. (1891b): España. Sus monumentos y artes. Su naturaleza é historia. Santander. Barcelona, Establecimiento Tipográfico-Editorial de Daniel Cortezo y Cía.

Amador de los Ríos y Fernández de Villalta, R. (1891c): Las pinturas de la Alhambra de Granada. Discurso leído en la recepción pública de Rodrigo Amador de los Ríos el día 17 de mayo de 1891; y contestación de Asenjo Barbieri. Madrid, Real Academia de Bellas Artes de San Fernando-Imprenta de Adolfo Ruiz de Castroviejo.

Amador de los Ríos y Fernández de Villalta, R. (1893a): "La conquista de Melilla". La Ilustración Española y Americana 37 (40): 262.

Amador de los Ríos y Fernández de Villalta, R. (1893b): "Melilla durante el siglo XVI". La Ilustración Española y Americana 37 (41): 281 y 284.

Amador de los Ríos y Fernández de Villalta, R. (1893c): "Melilla en los siglos XVII y XVIII". La Ilustración Española y Americana 37 (43): 318-319.

Amador de los Ríos y Fernández de Villalta, R. (1895a): "Epigrafía arábiga. Lápida conmemorativa descubierta en Toledo". Boletín de la Sociedad Española de Excursiones, 26: 41-44.

Amador de los Ríos y Fernández de Villalta, R. (1895b): "Epigrafía arábiga conmemorativa de la Capilla de Santa Catalina en Toledo. Rectificación”. Boletín de la Sociedad Española de Excursiones, 29: 104-106.

Amador de los Ríos y Fernández de Villalta, R. (1903a): “¡Viva España! Recuerdo de la última expedición a Melilla (1893)". La Ilustración Española y Americana 47 (6): 102.

Amador de los Ríos y Fernández de Villalta, R. (1903b): "El Museo Arqueológico Nacional: notas para su historia”. La España Moderna 1903 (2), 170: 41-70.
Amador de los Ríos y Fernández de Villalta, R. (1903c): "Recuerdos de un viaje por Huelva (1890)". La ESpaña Moderna 15 (180): 87-107.

Amador de los Ríos y Fernández de Villalta, R. (1906a): "Una excursión á las ruinas de Medina Az-Zahrá". La España Moderna 18 (211): 19-48.

Amador de los Ríos y Fernández de Villalta, R. (1906b): "De arte mahometano: las murallas de Niebla". Revista de Archivos, Bibliotecas y Museos 15 (9-10): 212-232.

Amador de los Ríos y Fernández de Villalta, R. (1908): Catálogo de Monumentos Históricos y Artísticos de la Provincia de Málaga, formado en virtud de R.O. de 22 de enero de 1907. Madrid, Manuscrito. Consejo Superior de Investigaciones Científicas. MCCHS, fondo antiguo, RECS 1190-1193 http://biblioteca.cchs.csic.es/digitalizacion_tnt/buscar.html Amador de los Ríos y Fernández de Villalta, R. (1909/1998): Catálogo de Monumentos Históricos y Artísticos de la Provincia de Huelva, formado en virtud de R.O. de 23 de noviembre de 1908, en M.J. Carrasco Terriza (ed.). Fascímil. Huelva, Diputación Provincial de Huelva.

Amador de los Ríos y Fernández de Villalta, R. (1911a): "Una excursión por Santiponce (Sevilla). En las ruinas de Itálica”. La España Moderna 23 (270): 73-89.

Amador de los Ríos y Fernández de Villalta, R. (1911b): "Itálica, el misterio de su destrucción y de su ruina". La España Moderna 23 (273): 5-25.

Amador de los Ríos y Fernández de Villalta, R. (1911c): "Itálica, dolorosas vicisitudes de su ruina". La España Moderna 23 (274): 92-110.

Amador de los Ríos y Fernández de Villalta, R. (1911d): "Las Ruinas de Itálica. Noticia de algunas de las excavaciones en ellas practicadas". La Ilustración Española y Americana, 15 de abril de 1911, 55 (14): 218-222.

Amador de los Ríos y Fernández de Villalta, R. (1911e): "Informe sobre declaración de monumento nacional de las ruinas de Itálica". Boletín de la Real Academia de Bellas Artes de San Fernando $2^{\text {a }}$ S. 20: 139-141.

Amador de los Ríos y Fernández de Villalta, R. (1912a): Catálogo de Monumentos Históricos y Artísticos de la Provincia de Albacete, formado en virtud de R.O. de 31 de marzo de 1911. Madrid, Manuscrito. Consejo Superior de Investigaciones Científicas. MCCHS, fondo antiguo, RECS 1101-1104 http://biblioteca.cchs.csic.es/digitalizacion_tnt/buscar.html Amador de los Ríos y Fernández de Villalta, R. (1912b): "El Museo de Antigüedades italicenses de la Excelentísima señora doña Regla Manjón, viuda 
de Sánchez Bedoya, en Sevilla". Revista de Archivos, Bibliotecas y Museos 27 (9-12): 269-289.

Amador de los Ríos y Fernández de Villalta, R. (1914a): Catálogo de Monumentos Históricos y Artísticos de la Provincia de Barcelona, formado en virtud de R.O. de 30 de abril de 1913. Madrid, Manuscrito. Consejo Superior de Investigaciones Científicas. M-CCHS, fondo antiguo, RECS 1117-1120 http://biblioteca.cchs.csic.es/digitalizacion_tnt/buscar.html

Amador de los Ríos y Fernández de Villalta, R. (1914b): "Las ruinas romanas del faro de Torrox (Málaga)". Revista de Archivos, Bibliotecas y Museos 31 (912): 237-241.

Amador de los Ríos y Fernández de Villalta, R. (1915a): "Errores inveterados: los supuestos 'baños árabes' de Gerona". Revista de Archivos, Bibliotecas y $\mathrm{Mu}$ seos 32 (5-6): 385-399.

Amador de los Ríos y Fernández de Villalta, R. (1915b): "Reliquias de los musulmanes en Cataluña". Revista de Archivos, Bibliotecas y Museos 33 (9-12): 173-212.

Amador de los Ríos y Fernández de Villalta, R. (1916a): "El Anfiteatro de Itálica. Noticias acerca de este monumento y de las excavaciones que en él, de orden del gobierno, se practican". Revista de Archivos, Bibliotecas y Museos 34 (5-6): 381-410 y 35 (7-8): 1-24.

Amador de los Ríos y Fernández de Villalta, R. (1916b): El Anfiteatro de Itálica. Memorias de la Junta Superior de Excavaciones y Antigüedades 1915 (4), 4. Madrid

Anónimo (1916): "Sección oficial y de noticias. D. Rodrigo Amador de los Ríos y Fernández de Villalta". Revista de Archivos, Bibliotecas y Museos 34 (34): 345-347.

Balmaseda Muncharaz, L.J. (2009): “Amador de los Ríos y Fernández-Villalta, Rodrigo”, en M. DíazAndreu, G. Mora y J. Cortadella (eds.), Diccionario histórico de la Arqueología en España: 81-82. Madrid, Marcial Pons Historia.

Barril, M. y Cerdeño, Ma.L. (1997): "El Marqués de Cerralbo: un aficionado que se institucionaliza", en G. Mora y M. Díaz-Andreu (eds.), La cristalización del pasado: génesis y desarrollo del marco institucional de la arqueología en España: 515-527. Málaga, Universidad de Málaga-C.S.I.C.-Ministerio de Educación y Cultura.

Betrán Fortes, J. (2002): “Descubrimientos arqueológicos en el anfiteatro de Itálica en 1914”. Spal 11: 365 375. http://dx.doi.org/10.12795/spal.2002.i11.18
Caballero Rodríguez, J. y Álvarez Martínez, J.Ma . (2011): Epistolario de las grandes excavaciones en Mérida. Correspondencia Privada entre Maximiliano Macías y José Ramón Mélida (1908-1934). Mérida, Consorcio Ciudad Monumental de Mérida-Museo Nacional de Arte Romano.

Casado Rigalt, D. (2006a): José Ramón Mélida (18561933) y la arqueología española. Anticuaria Hispánica 13. Madrid, Real Academia de la Historia.

Castañeda y Alcover, V. (1934): "El Excmo. Sr. D. José Ramón Mélida". Boletín de la Real Academia de Historia 104 (1): 5-40.

Codera y Zaidín, F. (1894): "Inscripción árabe de la capilla de Santa Catalina en Toledo". Boletín de la Real Academia de la Historia, 23 (5): 434-437.

Codera y Zaidín, F. (1895): "Inscripción árabe de la capilla de Santa Catalina en Toledo. Rectificación”. Boletín de la Sociedad Española de Excursiones, 28: 74-80.

Díaz-Andreu García, M. (2003): “Arqueología y Dictaduras: Italia, Alemania y España”, en F. Wulff y M. Álvarez (eds.), Antigüedad y Franquismo (19361975): 33-74. Málaga, Diputación Provincial de Málaga.

Díaz-Andreu García, M. (2004): “Mélida: génesis, pensamiento y obra de un maestro", en J.R. Mélida y Alinari, Arqueología Española: ix-clxviii. Pamplona, Urgoiti Editores.

Gamer-Wallert, I. (1998): "Una deidad del antiguo Egipto en Itálica”. Revista de Arqueología 19 (206): 6-9.

García y López, J.C. (1894): La Alcarria en los dos primeros siglos de la reconquista. Discursos leidos ante la Real Academia de la Historia en la recepción pública del Excmo. Señor D. Juan Catalina García y López el 27 de mayo de 1894. Contestación del Excelentísimo Señor D. Juan de Dios de la Rada y Delgado. Madrid, El Progreso EditorialReal Academia de la Historia.

Gayangos y Arce, P. de (1848): "Dos inscripciones cúficas arábigas de Toledo". Semanario Pintoresco Español 20: 153-156.

Gayangos y Arce, P. de (1851): “Inscripciones arábigas”. Memorial Histórico Español 2: 393-400.

Gayangos y Arce, P. de (1852): "Inscripciones arábigas". Memorial Histórico Español 3: 409-419.

Gayangos y Arce, P. de (1853): "Inscripciones arábigas de Córdoba". Memorial Histórico Español 6: 311-325.

Gayangos y Arce, P. de (1861): Principios elementales de la escritura arábiga y modelo de lectura. Madrid. 
Gómez-Moreno Martínez, M. (1951-58/1977): “Un currículum vitae, autógrafo, del maestro GómezMoreno", en J. de M. Carriazo, El maestro GómezMoreno contado por el mismo. Discurso leído el día 8 de Mayo de 1977, en su recepción pública, por el Excmo. Sr. D. Juan de Mata Carriazo y Arroquia y contestación del Excmo. Sr. D. Emilio García Gómez: 53-62. Sevilla, Real Academia de la Historia.

Gómez-Moreno Martínez, M. (1952/1972): "Don Manuel cuenta su vida en los años decisivos". Homenaje a Gómez-Moreno 1870-1970: 9-31. Granada, Universidad de Granada.

Gómez-Moreno Rodríguez, M.E. (1991): La Real Academia de San Fernando y el origen del Catálogo Monumental de España. Discurso de la académica electa Excma. Sra. Doña María Elena Gómez-Moreno leído en el acto de su recepción pública el día 3 de noviembre de 1991. Contestación del Excmo. Sr. D. Joaquín Pérez Villanueva. Madrid, Real Academia de Bellas Artes de San Fernando.

Gómez-Moreno Rodríguez, Ma.E. (1995): Manuel Gómez-Moreno Martínez. Madrid, Centro de Estudios Ramón Areces.

Hübner, E. (1869): Corpus Inscriptionum Latinarum. II. Inscriptiones Hispaniae Latinae. Berolini-Berlin, Academiae Litterarum Regiae Borussiae. Georgium Reimerum.

Lafuente Alcántara, E. (1859): Inscripciones árabes de Granada, precedidas de una reseña histórica y de la genealogía detallada de los reyes Alahmares. Granada, Imprenta Nacional.

López Grande, M‥J. (2004): "El viaje a Egipto. Primeros viajeros españoles y primeras miradas de la investigación española hacia las tierras del Nilo". Cuadernos de Prehistoria y Arqueología de la Universidad Autónoma de Madrid 30: 225-239.

Mélida y Alinari, J.R. (1907): Discurso de contestación a don Narciso Sentenach, en el acto de su recepción pública en la Real Academia de Bellas Artes de San Fernando, el día 13 de octubre de 1907. Madrid, Imprenta de San Francisco de Sales.

Mélida y Alinari, J.R. (1917): “Adquisiciones del Museo Arqueológico Nacional en 1916. Notas descriptivas". Revista de Archivos, Bibliotecas y Museos $3^{\mathrm{a}}$ S. 37 (7-8): 8-27.

Mederos Martín, A. (2013): “Análisis de una decadencia. La arqueología española del siglo XIX. II. La crisis de la Restauración (1868-1885)". Cuadernos de Prehistoria y Arqueología de la Universidad Autónoma de Madrid 39: 201-243.
Mederos Martín, A. (e.p.): “A la sombra de Cerralbo. Catalina García y López, primer catedrático de Arqueología y director del Museo Arqueológico Nacional (1900-1911)". Boletín del Seminario de Estudios de Arqueología 80.

Pavón y López, F. de B. (1978): “El Excmo. Sr. D. José Amador de los Ríos y Padilla". Boletín de la Real Academia de Córdoba de Ciencias, Bellas Letras y Nobles Artes 48 (99): 155-157.

Papí Rodes, C. (2004): “Juan de Dios de la Rada y Delgado", en M. Ayarzagüena y G. Mora (eds.), Pioneros de la Arqueología en España del siglo XVI a 1912. Zona Arqueológica 3: 253-260.

Pasamar, G. y Peiró, I. (2002): Diccionario Akal de Historiadores españoles contemporáneos (18401980). Madrid, Akal.

Pérez-Villamil García-Somolinos, M. (1907): Establecimiento e instituto de la Orden militar de Santa María de España. Discursos leídos ante la Real Academia de la Historia en la recepción pública del Excelentísimo Sr. D. Manuel Pérez Villamil en 12 de marzo de 1907. Contestación del Excmo. Sr. D. Juan Catalina García. Madrid, Real Academia de la Historia.

Puig i Cadafalch, J.; Falguera, A. de y Goday, J. (1911): L'Arquitectura romanica a Catalunya. Barcelona, Institut d'Estudis Catalans.

Rada y Delgado, J. de D. de la (1884): "Las peregrinaciones a La Meca". Revista Contemporánea 49 (1): 447-475.

Rada y Delgado, J. de D. de la (1884/2005): Las peregrinaciones a La Meca en el siglo XIX, en J.L. Sánchez (ed.). Facsímil. Madrid, Miraguano Ediciones.

Rada y Delgado, J. de D. de la (1893): Catálogo general de la Exposición Histórico-Americana de Madrid. 1892. Cuarto centenario del descubrimiento de América. I-II. Madrid, Establecimiento Tipográfico Sucesores de Rivadeneyra.

Rada, J. de D. de la; [Vives, A. y Codera, F.] (1892): Catálogo de monedas arábigas españolas que se conservan el Museo Arqueológico Nacional publicado siendo Director del mismo D. Juan de Dios de la Rada y Delgado. Madrid, Establecimiento tipográfico de Fortanet.

Ríos y Serrano, J. Amador de los y Amador de los Ríos y Fernández de Villalta, R. (1879): Monumentos Latino-Bizantinos de Córdoba. I-II. Monumentos Arquitectónicos de España. Madrid, Imprenta y calcografía Nacional.

Rodríguez González, A.R. (2008): La guerra de Melilla en 1893. Madrid, Almena Ediciones. 
Rodríguez Oliva, P. y Beltrán Fortes, J. (2008): “Arqueología de Andalucía. Algunos ejemplos de actividades arqueológicas en la primera mitad del siglo XX", en J. Beltrán Fortes y M. Habibi (eds.), Historia de la Arqueología en el norte de Marruecos durante el periodo del Protectorado y sus referentes en España: 39-61. Sevilla, Universidad Internacional de Andalucía-Universidad de Sevilla.

Simonet, F.J. y Lerchundi, J. (1881): Crestomatía arábigo-española ó Colección de fragmentos históricos, geográficos y literarios relativos a España bajo el periodo de la dominación sarracénica, seguida de un vocabulario de todos los términos contenidos en dichos fragmentos. Granada, Imprenta de Indalecio Ventura.
Simonet, F.J. y Lerchundi, J. (1883): Crestomatía arábigo-española. $2^{a}$ parte, vocabulario arábigo-español. Granada, Imprenta de Indalecio Ventura Sabatel. Valverde y Perañes, F. (1903): "D. José Amador de los Ríos", en Historia de la Villa de Baena: 418-433. Toledo, Imprenta y librería de la Viuda e hijos de J. Peláez.

Vargas-Zúñiga, A., Marqués de Siete Iglesias (1981): Real Academia de la Historia. Catálogo de sus individuos. Noticias sacadas de su archivo. I. Académicos de Número. Madrid, Real Academia de la Historia.

Zapata Parra, J.A. (2006): "Rodrigo Amador de los Ríos y la provincia de Murcia", en Espacio y tiempo en la percepción de la Antigüedad Tardía. Antigüedad y Cristianismo 23: 913-936. 